\title{
Curcumin/Tween 20-incorporated cellulose nanoparticles with enhanced curcumin solubility for nano-drug delivery: characterization and in vitro evaluation
}

Article

Accepted Version

Ching, Y. C., Gunathilake, T. M. S. U., Chuah, C. H., Ching, K. Y., Singh, R. and Liou, N.-S. (2019) Curcumin/Tween 20incorporated cellulose nanoparticles with enhanced curcumin solubility for nano-drug delivery: characterization and in vitro evaluation. Cellulose, 26 (9). pp. 5467-5481. ISSN 5467-5481 doi: https://doi.org/10.1007/s10570-019-02445-6 Available at https://centaur.reading.ac.uk/102062/

It is advisable to refer to the publisher's version if you intend to cite from the work. See Guidance on citing.

To link to this article DOI: http://dx.doi.org/10.1007/s10570-019-02445-6

Publisher: Springer

All outputs in CentAUR are protected by Intellectual Property Rights law, including copyright law. Copyright and IPR is retained by the creators or other copyright holders. Terms and conditions for use of this material are defined in the End User Agreement. 


\section{www.reading.ac.uk/centaur}

\section{CentAUR}

Central Archive at the University of Reading

Reading's research outputs online 


\section{Curcumin/Tween 20-incorporated cellulose nanoparticles with enhanced curcumin}

\section{2 solubility for nano-drug delivery: characterization and in vitro evaluation}

3 Yern Chee Ching. Thennakoon M. S. U. G. Cheng Hock Chuah- Kuan Yong Ching. Ramesh

4 Singh. Nai-Shang Liou

5

6 a Department of Chemical Engineering, Faculty of Engineering, University of Malaya, 50603

$7 \quad$ Kuala Lumpur, Malaysia

8 b Department of Chemistry, Faculty of Science, University of Malaya, 50603 Kuala Lumpur,

9 Malaysia

10 c University of Reading Malaysia, Persiaran Graduan, Kota Ilmu, Educity, 79200 Iskandar

11 Puteri, Johor, Malaysia

12 d Department of Mechanical Engineering, Faculty of Engineering, University of Malaya, 50603

13 Kuala Lumpur, Malaysia

14 e Department of Mechanical Engineering, Southern Taiwan University of Science and

15 Technology, 710 Tainan City, Taiwan, ROC

16

17

18

19

20

21

22

23

24

25

26

27 


\section{Abstract}

29 A poorly water-soluble anticancer drug, curcumin was loaded in to cellulose nanocrystals by dissolving it in a commonly used nonionic surfactant medium. Results showed that the drug

31 loading capacity of nanocellulose increased with increasing the surfactant concentration of the

32 medium.The drug loading capacity of nanocellulose in surfactant medium was significantly

33 higher $(7.73 \mathrm{mg} / \mathrm{g})$ when compared to the drug loading capacity $(3.35 \mathrm{mg} / \mathrm{g})$ in methanolic 34 medium. The nanocellulose drug loaded in surfactant medium (TW/CNC) showed higher drug 35 release compared to the nanocellulose drug loaded in methanolic medium (METH/CNC). It was $368.99 \mathrm{mg} / \mathrm{L}$ for TW/CNC and $2.65 \mathrm{mg} / \mathrm{L}$ for $\mathrm{METH} / \mathrm{CNC}$ in simulated gastric fluid. Due to the 37 increased stability of curcumin in acidic medium, all the nanoparticles showed higher drug 38 release in simulated gastric fluid compared to phosphate buffered saline solution. The maximum 39 dissolution of curcumin was $2.13 \mathrm{mg} / \mathrm{mL}$ in distilled water containing $4 \%(\mathrm{w} / \mathrm{v})$ of surfactant. $40 \mathrm{UV}$-visible spectra revealed that the curcumin retained its chemical activity after in vitro release. 41 From these findings, it is believed that the incorporation of curcumin into nanocellulose in 42 surfactant medium provides a promising approach for delivery of curcumin to stomach and upper 43 intestinal tract.

44 Key words: Nanocellulose, Curcumin, Tween 20, Bioavailability 
50 Nanotechnology is playing a key role in a broad range of applications. Since its introduction, it is

51 a key component of advancing almost all areas of science, particularly, drug delivery and

52 formulation. Today, nanotechnology is being applied in the areas of drug delivery and

53 formulations known as 'Nanopharmaceutics'. As nanoparticles are accepted by cells more

54 effectively than larger microparticles, they can be used as efficient transport and delivery

55 systems. Nanostructured-based drug delivery systems offer many advantages over conventional

56 drug delivery systems, including their ability to pass through the narrow capillary vessels due to

57 their smaller size, ability to penetrate cells and tissue gap to arrive at target organs and to provide

58 controlled drug release over a prolong period (Rizvi and Saleh 2017). Nanoparticles exhibit

59 greater drug uptake compared to microparticles. The small dimensions of nanoparticles

60 compared to their bulk counterparts bring drug more closer to the surface of the particle, which

61 results in faster drug release (Rizvi and Saleh 2017).With the increase in potential usefulness of

62 nanoparticles in therapeutics delivery, knowledge on the health effects of the nanoparticle

63 exposure and the basics of the interaction of nanoparticles with living cells, organs and

64 organisms is still limited. In this respect, materials and strategies which minimize the

65 possibilities of causing adverse and toxic effectshave been developed for therapeutic delivery, in

66 particular the choice of biodegradable nanoparticles with a limited life span which avoid the

67 accumulation in the liver and spleen(Gustafson et al. 2015).

68 Nanocellulose is a biodegradable nanomaterial which is obtained by most abundant natural

69 polymer on earth. Nanocelluloses and their derivatives are attractive candidates for controlled

70 drug delivery systems due to their biocompatibility, biodegradability and stimuli-responsiveness.

71 It has been investigated for the delivery of protein, poorly water soluble drugs such as 
72 beclomethasone, diproprionate, indomethacin and itraconazol from previous studies (Löbmann

73 and Svagan 2017. The unique physico-chemical, rheological and barrier properties of

74 nanocellulose provide them to stabilize air/water and oil/water interfaces (Löbmann and Svagan

75 2017). Also, their large surface area-to-volume ratios offer possibilities for positive molecular

76 interactions with poorly-soluble drugs. The acid hydrolysis is an economical method that have

77 been extensively used for nanocellulose extraction from various natural sources such as plant

78 fiber, wood fiber, microcrystalline cellulose, algae, tunicate and bacteria. Nanocellulose

79 synthesized using acid hydrolysis has a size range from $10 \mathrm{~nm}$ to $350 \mathrm{~nm}$ (Phanthong et al. 2015;

80 Sadeghifar et al. 2011; Sampath et al. 2017). Numerous studies have reported relationship

81 between nanoparticle size and biological adverse effects (Gustafson et al. 2015). From the

82 literature it was reported that the optimum size for nanoparticle as carriers for drug delivery is 83 approximately $100 \mathrm{~nm}$ (Rizvi and Saleh 2017). Thereby, acid hydrolysis can be used to produce

84 the nanocelluloses with optimal size which is suitable for drug delivery.

85 Curcumin is a polyphenol obtained from the plant Curcumalonga. Curcumin has received 86 worldwide attention due to its promising anti-cancer properties (Ibrahim et al. 2018). Also, it can

87 cause a high rate of Helicobacter pylori eradication which was identified as a group I 88 carcinogenic agent of human gastric cancer (De et al. 2009; Santos et al. 2018). However, the 89 complete potential of curcumin has not been successfully utilized due of its poor water solubility 90 and low bioavailability. Several strategies have been developed to enhance the solubility and 91 bioavailability of curcumin such as formation of micelles, nanosuspensions, nanoparticles and 92 nano-emulsions are some of them (Kamaraj et al. 2018). Solid dispersion is one of efficient 93 method to overcome the challenges associated with poor water solubility of drugs. However the 94 miscibility and stability of the dispersion are main limitations related with the development of 
95 solid dispersions. The use of surfactant in solid dispersion can overcome these limitations 96 (Chaudhari and Dugar 2017). Surfactants can be cationic, anionic, nonionic or amphoteric. When

97 surfactant molecules are dissolved in water at a concentration greater than critical micelle 98 concentration $(\mathrm{cmc})$, they form spherical form of aggregates known as micelles. The solubility of 99 hydrophobic drugs in nonionic surfactant solutions is greater than compared to solubility in ionic 100 surfactant solutions, because of their lower cmc values (Rangel-Yagui et al. 2005). In a micelle, 101 the hydrophobic tails of several surfactant molecules flock into oil-like core in order to minimize 102 their contact with water, and the hydrophilic heads region faces the outside surface of the micelle 103 in order to maximize their contact with water.

104 Although research on nanocellulose based drug delivery systems are exponentially growing, 105 there are a few reports that have been published on nanocellulose/curcumin drug delivery 106 systems (de Castro et al. 2018; Mohan Yallapu et al. 2012; Ntoutoume et al. 2016). Inspired by 107 our previous work (Gunathilake et al. 2018; Udeni Gunathilake et al. 2017), we continued our 108 investigation on the enhancement of bioavailability of curcumin. From our previous study, 109 curcumin and nonionic surfactant were incorporated into nanocellulose reinforced chitosan 110 hydrogel and studied the drug delivery behavior. We observed that the cumulative drug release 111 of the hydrogel increased with increasing the nonionic surfactant concentration. However, the 112 drug loading efficiency of the hydrogel decreased with the incorporation of the surfactant to the 113 hydrogel (Gunathilake et al. 2018). Furthermore, the addition of nanocellulose enhanced the 114 mechanical strength and swelling behavior of the hydrogel (Sampath et al. 2017).However, the 115 problems encountered in previous study were the decrease of encapsulation efficiency of the 116 drug with increasing of surfactant concentration and incomplete drug release profiles. Polymer 117 phase of chitosan hydrogel acted as a diffusion barrier against movement of drug in the previous 
study. Due to the hydrophilic property of the surfactant (high HLB value), the intake of water has narrowed the diffusion barrier. Hence the entrapment efficiency decreased with increasing of surfactant. In this study, the increase of surfactant concentration will improve the micelle formation and it will facilitate incorporation of drug into nanocellulose and hence, result in improvement of encapsulation efficiency. Previous study showed incomplete drug release profiles over the time of monitoring. This is due to the fact that the embedded drug released slowly over a longer period of time by diffusion through the hydrogel matrix. In this study, the small dimensions of nanoparticles bring drug closer to the surface of the nanocellulose particles which results in faster drug release.This will lead to complete drug release during shorter residence time of the dosage form in the stomach. Therefore, the curcumin/Tween 20 incorporated cellulose nanoparticle system will provide a better platform to overcome the problems associated with the curcumin/nanocellulose reinforced chitosan hydrogel system as described in our previous study (Gunathilake et al. 2018).

In this study, we dissolved hydrophobic drug (curcumin) in a commonly used nonionic surfactant solution and incorporated in to nanocellulose, which synthesized from microcrystalline cellulose by sulphuric acid hydrolysis method. Depending on the arrangement of hydrophobic and hydrophilic groups of surfactant molecules in the micelle structure, there may be different interactions canoccur with drug molecules and cellulose nanocrystals. Hydrophobic drug (curcumin) may be located in the inner core of the micelle of nonionic surfactant and the hydrophilic groups of nonionic surfactants may have affinity for adsorption to cellulose, because of its hydroxyl groups. Tween is a non-ionic surfactant commonly used in drug delivery applications for dispersing of hydrophobic drugs. They consist of two different groups: a hydrophilic head group and a hydrophobic alkyl chain. Based on the alkyl chain length, there are 
141 different types of Tween surfactants namely, Tween 20, 40, 60 and 80. The differences of the 142 alkyl chain length of surfactants influence the hydrophile-lipophile balance (HLB) value of the 143 surfactant and the entrapment efficiency of drug delivery systems. Increasing the alkyl chain 144 length (the surfactants with lower HLB values) is leading to higher entrapment efficiency. The 145 higher the chain length (surfactants with lower HLB values), would cause lower release rates of 146 hydrophobic drugs. This is due to the fact that the surfactants having lower HLB values are more 147 lipophilic and less water soluble. But, the surfactants with higher HLB values such as Tween 20 $148(\mathrm{HLB}=16.7)$ helps to improve the release rates of hydrophobic drugs to a desired extent. 149 According to the findings of this study, we envision that our proposed curcumin/nonionic 150 surfactant-incorporated cellulose nanoparticle drug delivery system has great potential for 151 enhancing the bioavailability of curcumin.

152

\section{Experimental methodology}

154 Materials

155 Microcrystalline cellulose, Tween 20 and phosphate-buffered saline were supplied by R\&M 156 chemicals (Essex, UK). Sodium chloride, hydrochloric acid, methanol and sulfuric acid were 157 purchased from Friendemann Schmidt Chemicals (Parkwood, Australia). The drug curcumin was 158 provided by HIMEDIA laboratories Pvt Ltd. (Mumbai, India).

159 Methodology

Extraction of curcumin from turmeric

161 Curcumin was extracted from turmeric (rhizomes of Curcuma longa) by solvent extraction 162 method Rhizomes were dried, crushed and soaked in methanol for 3 days. After that, the extract 
163 was filtered with Whatman filter paper (pore size $0.2 \mu \mathrm{m}$ ). Finally, the filtrate was evaporated 164 under vacuum to obtain semi-dry oily mass.

165 FTIR study

166 The FTIR spectra of curcumin extracted from rhizomes of curcuma longa, Tween 20, 167 nanocellulose and curcumin loaded nanocellulose were obtained using PerkinElmer spectrum 168400 FTIR spectrometer over the range $4000-400 \mathrm{~cm}^{-1}$.

$169 \quad X$-ray diffraction

170 The crystallinity degrees of curcumin, nanocellulose and curcumin incorporated

171 nanocelulosewere studied using X-ray diffractometer (PANalytical EMPYREAN

172 diffractometer). The samples were dried and powdered before they were analyzed. The samples

173 were exposed to $\mathrm{Cu} \mathrm{K} \alpha$ radiation generated at $40 \mathrm{~mA}, 40 \mathrm{kV}$, a $2 \theta$ angle of $5-60^{\circ}$, and a scan rate 174 of $6 \% \mathrm{~min}$

\section{Drug loading}

176 Cellulose nanocrystals (CNC) were synthesized by sulfuric acid hydrolysis of microcrystalline 177 cellulose, as reported in our previous study (Sampath et al. 2017). To prepare curcumin loaded 178 nanocellulose in Tween 20 medium, excess amount of curcumin were mixed with different 179 concentrations of Tween $20(0.8 \%, 1.6 \%, 2.4 \%, 3.2 \%, 4 \%, 4.8 \%, 5.6 \%(\mathrm{w} / \mathrm{v}))$ and stirred for 24 180 h. Then, the curcumin solutions (in Tween 20 medium) were centrifuged (10,000 rpm for 10 $181 \mathrm{~min}$ ) and supernatants were collected. After that, a constant amount of nanocellulose was mixed 182 with each curcumin solution (in Tween 20 medium) and stirred for $24 \mathrm{~h}$. To prepare curcumin 183 loaded nanocellulose in methanolic medium, constant amount of nanocellulose (similar to use in 
184 Tween medium) was mixed with different concentrations (similar to the dissolved amount of 185 curcumin present in Tween 20 solutions) of curcumin solutions (prepared by dissolving 186 curcumin in methanol and diluting with distilled water) and stirred $24 \mathrm{~h}$. After that, the 187 suspension was centrifuged $6000 \mathrm{rpm}$ for $20 \mathrm{~min}$ and supernatant was decanted and the 188 remaining amount ofcurcumin was determined using UV-Vis spectroscopic method. The drug 189 loading capacity was calculated based on the ratio of the absorbed amount of the drug from the 190 solution to the weight of the nanocellulose (Eq. (1)).

191 .Drug loading capacity $=\frac{\text { Absorbed amount of drug from the solution }}{\text { Weight of nanocellulose }}(1)$

192 Drug release

193 In vitro drug release from drug loaded nanocellulose was studies in simulated gastric fluid 194 (SGF) (prepared by dissolving $2 \mathrm{~g} \mathrm{NaCl}$ in $7.0 \mathrm{~mL} \mathrm{HCl}$ and water up to $1000 \mathrm{~mL}$ ) and phosphate 195 buffer saline solution (PBS) at $37{ }^{\circ} \mathrm{C}$. In order to study the release, at prefixed time intervals, 3 $196 \mathrm{~mL}$ of medium was withdrawn and returned it back to the solution after the analysis. The 197 concentration of curcumin was determined using UV-Vis spectroscopic method. The 198 experiments were replicated three times and average values were taken. The types of 199 nanocellulose used for drug release studies are as per the details mentioned in Table 1.

200 Table 1 Types of nanocelluloseused for the drug release studies (based on the drug loading and 201 releasing medium).

\begin{tabular}{|l|c|l|l|l|}
\hline $\begin{array}{l}\text { Types of } \\
\text { nanocellulose } \\
\text { (based on the } \\
\text { drug loading and } \\
\text { releasing } \\
\text { medium) }\end{array}$ & $\begin{array}{l}\text { Weight of } \\
\text { nanocellulose }(\mathrm{g})\end{array}$ & $\begin{array}{l}\text { Amount of drug } \\
\text { (curcumin) } \\
\text { loaded per 1 g of } \\
\text { nanocellulose } \\
(\mathrm{mg})\end{array}$ & $\begin{array}{l}\text { Drug loading } \\
\text { medium }\end{array}$ & $\begin{array}{l}\text { Drug releasing } \\
\text { medium }\end{array}$ \\
\hline TW/CNC-SGF & 1 & 7.73 & $\begin{array}{l}\text { Aqueous solution } \\
\text { of Tween 20 }\end{array}$ & $\begin{array}{l}\text { Simulated gastric } \\
\text { fluid }\end{array}$ \\
\hline
\end{tabular}




\begin{tabular}{|l|c|c|l|l|}
\hline TW/CNC-PBS & 1 & 7.73 & $\begin{array}{l}\text { Aqueous solution } \\
\text { of Tween 20 }\end{array}$ & $\begin{array}{l}\text { Phosphate } \\
\text { buffered saline } \\
\text { solution }\end{array}$ \\
\hline $\begin{array}{l}\text { METH/CNC- } \\
\text { SGF }\end{array}$ & 1 & 3.35 & $\begin{array}{l}\text { Methanolic } \\
\text { medium }\end{array}$ & $\begin{array}{l}\text { Simulated gastric } \\
\text { fluid }\end{array}$ \\
\hline $\begin{array}{l}\text { METH/CNC- } \\
\text { PBS }\end{array}$ & 1 & 3.35 & $\begin{array}{l}\text { Methanolic } \\
\text { medium }\end{array}$ & $\begin{array}{l}\text { Phosphate } \\
\text { buffered saline } \\
\text { solution }\end{array}$ \\
\hline
\end{tabular}

Solubility studies of curcumin in distilled water

To determine the solubility of curcumin in distilled water, an excess amount of curcumin extract was added to $30 \mathrm{~mL}$ of distilled water and mixed with different concentrations of Tween 20 using magnetic stirrer for $12 \mathrm{~h}$. Samples were covered in order to prevent photo-degradation.

209 After that, the solutions were centrifuged (10,000 rpm for $10 \mathrm{~min})$ to separate the undissolved 210 curcumin and the dissolved curcumin was determined using UV-Vis spectroscopic method.

212 The drugs are often inevitable and therefore, the chemical reactivity related to biological activity

213 of the drug is most important parameter to be concerned when selecting a drug delivery carrier.

214 The UV-Vis spectra of pure drug and released drug can be used to determine if any deterioration 215 reaction happened due to the destructive interactions between drug and carrier molecules 216 (Bashir et al. 2016). The UV-visible spectra of pure drug and the drug released from the cellulose 217 nanoparticles were obtained by scanning the drug solutions using UV-visible spectrophotometer 218 (scan range 300-800 $\mathrm{nm}$ ). Drug activity was determined by comparing the spectra (the absorption maxima $(\lambda \max ))$ of pure drug and drug released from nanocellulose. 


\section{Results and discussion}

\section{$221 \quad$ FTIR study}

222 Fig. 1 displays the FTIR spectra of curcumin, nonionic surfactant, nanocellulose, drug loaded 223 nanocellulose in surfactant medium and drug loaded nanocellulose in methanolic medium. The

224 IR spectrum of curcumin derived from turmeric is more similar to the IR spectrum of crystalline 225 curcumin derived from turmeric powder, which was reported in previous studies(Bich et al. 226 2009; Fugita et al. 2012). From our previous study, we have compared and characterized the 227 FTIR spectra of extracted curcumin and curcumin purchased from Himedia Co. (Gunathilake et 228 al. 2018). In the FTIR spectrum of curcumin, the highest frequency bands observed within 2700$2293000 \mathrm{~cm}^{-1}$ region are assigned to the aromatic $\mathrm{C}-\mathrm{H}$ stretches (Kolev et al. 2005). The IR bands at $230815 \mathrm{~cm}^{-1}$ and $720 \mathrm{~cm}^{-1}$ belongs to the $v(\mathrm{C}-\mathrm{H})$ out of plane vibration of the aromatic ring (Kolev et 231 al. 2005). In the range of $700-500 \mathrm{~cm}^{-1}$, we couldsee deformation vibrations of both benzene 232 rings and the out of plane vibrations of both $\mathrm{OH}$ groups, which are at $607 \mathrm{~cm}^{-1}$ and $546 \mathrm{~cm}^{-1}$ 233 (Bich et al. 2009). These aromatic groups provide much of the hydrophobicity to the curcumin 234 molecules. Due to these hydrophobic groups, curcumin molecules are located in the core of the 235 surfactant micelles, when it dispersed in surfactant solution. The peak at $1679 \mathrm{~cm}^{-1}$ appeared due 236 to the $\mathrm{C}=\mathrm{O}$ vibrations (Bich et al. 2009). The most prominent band in the IR spectrum is at 1509 $237 \mathrm{~cm}^{-1}$ can be attributed to highly mixed vibrations $\left({ }^{v} \mathrm{C}=\mathrm{O},{ }^{\delta} \mathrm{CC}{ }^{10} \mathrm{C},{ }^{\delta} \mathrm{CC}=\mathrm{O}\right)(\mathrm{Bich}$ et al. 2009). 238 These ketone group exhibits keto-enoltautomerism forming a predominant keto form in acidic 239 and neutral media and stable enol form in alkaline medium. Therefore, it is insoluble in water 240 under acidic or neutral pHs but dissolves in alkaline conditions(Jankun et al. 2016). 
241 In the FTIR spectrum of the nonionic surfactant, the peak around $3522 \mathrm{~cm}^{-1}$ is due to the 242 hydrogen bonded O-H stretching vibrations. The peaks at $2935 \mathrm{~cm}^{-1}$ and $2883 \mathrm{~cm}^{-1}$ are due to the 243 asymmetric and symmetric methylene stretching vibrations. The $1741 \mathrm{~cm}^{-1}$ peak represents the 244 carbonyl group from R-CO-O-R and the peak at $1667 \mathrm{~cm}^{-1}$ attributed to the carbonyl stretching.

245 The most prominent peak at $1103 \mathrm{~cm}^{-1}$ is due to the stretching vibration of $-\mathrm{CH}_{2}-0-\mathrm{CH}_{2}-(\mathrm{Ortiz}-$ 246 Tafoya and Tecante 2018).

247 In the FTIR spectrum of nanocellulose, the broad band at $3334 \mathrm{~cm}^{-1}$ is due to the characteristic $248 \mathrm{OH}$ stretching from vibrations in the intra-and intermolecular hydrogen-bonded hydroxyl groups 249 (Gunathilake et al. 2017). The band at $2901 \mathrm{~cm}^{-1}$ is corresponded to aliphatic saturated $\mathrm{CH}-$ 250 stretching in the glucose units. Other peaks detected include the adsorption band at $1636 \mathrm{~cm}^{-1}$ 251 which is due to the absorption of water onto cellulose, the peak at $1428 \mathrm{~cm}^{-1}$ associated with $252 \mathrm{CH}_{2}$ symmetrical bending and scissoring motion in cellulose, the peak at $1159 \mathrm{~cm}^{-1}$ is due to the 253 asymmetrical bridge $\mathrm{C}-\mathrm{O}-\mathrm{C}$ stretching from theglycosidic bond, the band at $1029 \mathrm{~cm}^{-1}$ 254 representing stretching of the glucopyranose unit and the peak at $896 \mathrm{~cm}^{-1}$ is typical of the $\beta$ 255 glycosidic linkage in cellulose (Ching \& Ng 2014, Sahlin et al. 2018).

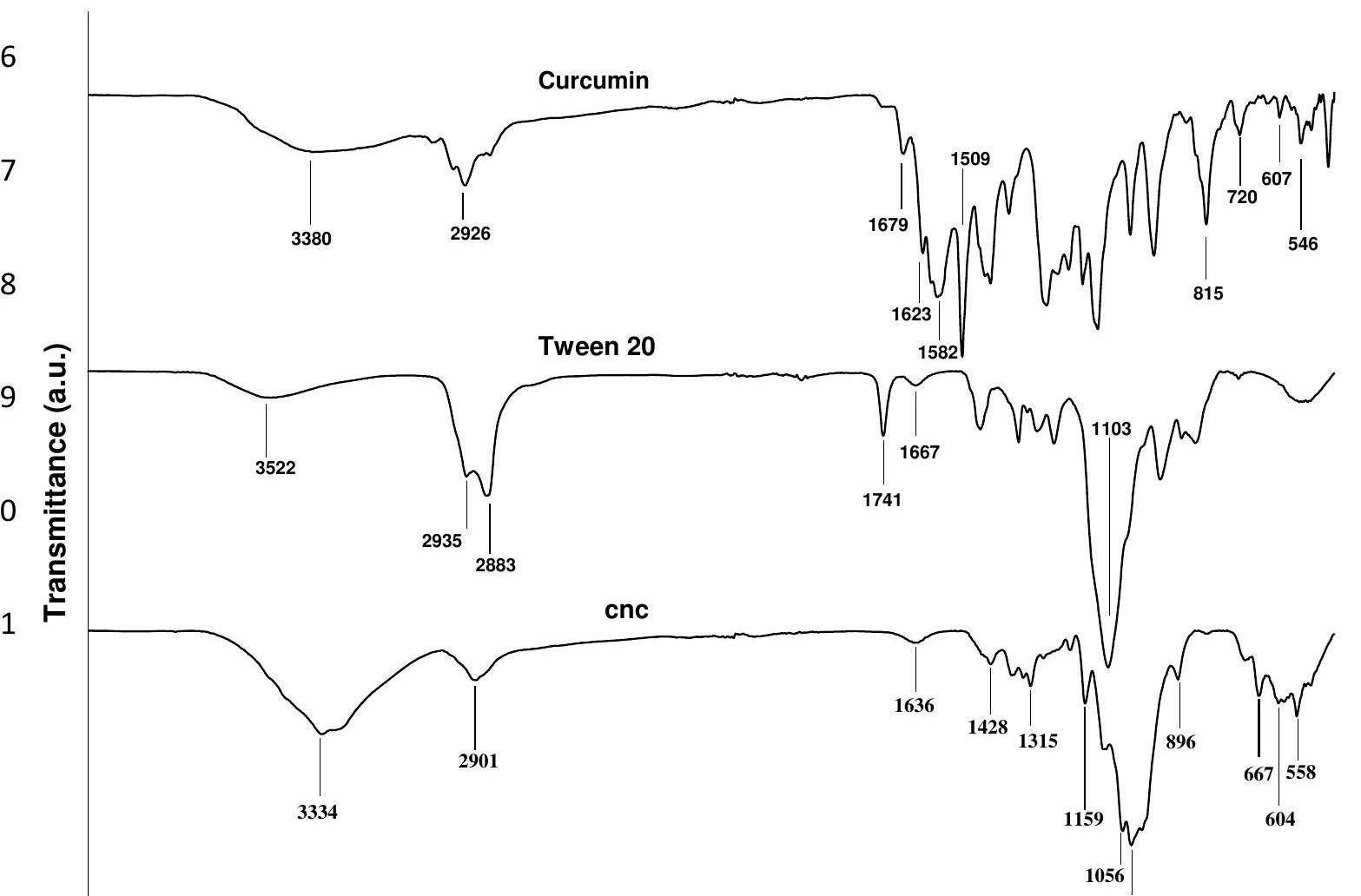


Fig. 1 FTIR spectra of curcumin, nonionic surfactant and nanocellulose (CNC)

266 From the FTIR spectrum of nanocellulose drug loaded in methanolic medium

267 (curcumin/cnc/methanolic medium), it can be seen that the bands corresponding to the functional 268 groups of $\mathrm{CNC}$ are more prominent (Fig. 2). However, small peaks at $1635 \mathrm{~cm}^{-1}$ and $2691595 \mathrm{~cm}^{-1}$ are appeareddue to the $v(\mathrm{C}=\mathrm{C})$ of the benzene ring, mixed $v(\mathrm{C}=\mathrm{C})$ and $v(\mathrm{C}=\mathrm{O})$ groups 270 of curcumin(Bich et al. 2009; Mohan et al. 2012).Also in the FTIR spectrum of nanocellulose 271 drug loaded in surfactant medium(curcumin/cnc/surfactant medium), the bands corresponding to 272 the functional groups of CNC are prominent. In this spectrum a sharp peak appeared at 1652 $273 \mathrm{~cm}^{-1}$ which represents the carbonyl group from R-CO-O-R of Tween 20(Ortiz-Tafoya and 274 Tecante 2018). However, no new peak appeared in both spectrum of curcumin/cnc/methanolic 275 medium and curcumin/cnc/surfactant medium.

276

277

278

279

280

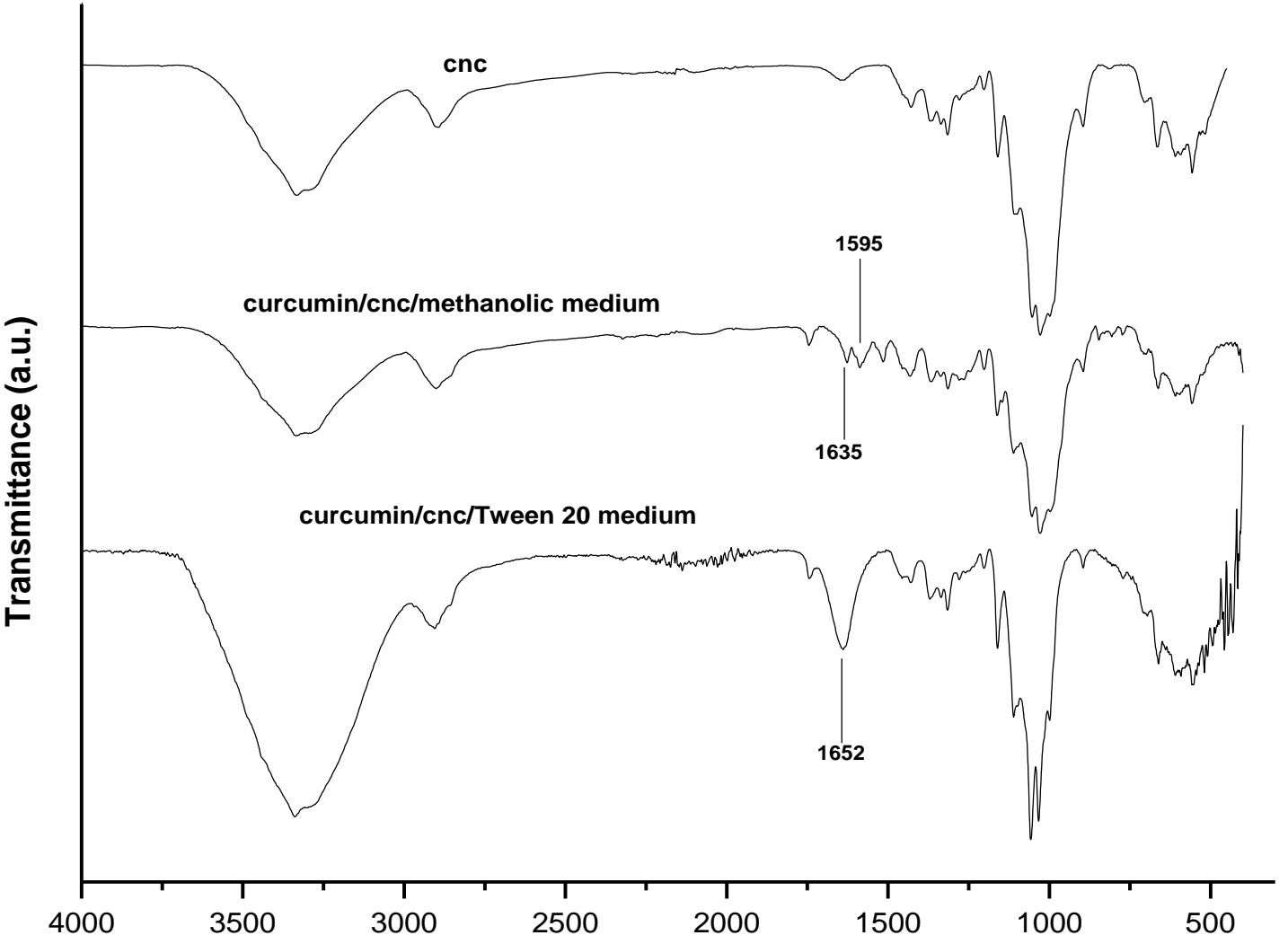


284 Fig. 2 FTIR spectra of cellulose nanoparticles, curcumin loaded cellulose nanoparticles in 285 methanolic medium and curcumin loaded cellulose nanoparticles in surfactant medium

$286 \quad X$-ray diffraction analysis

287 The X-ray diffraction (XRD) patterns of the curcumin, nanocellulose and curcumin incorporated 288 nanocellulose were investigated via powder XRD analysis (Fig. 3). As shown in the 289 diffractogram, the $\mathrm{CNC}$ exhibited peaks around $2 \theta=15^{\circ}, 16.5^{\circ}, 20.5^{\circ}, 22.5^{\circ}, 34.5^{\circ}$, which 290 respectively represent the (1-10), (110), (102), (200), and (004) crystallographic planes of a 291 typical cellulose I structure (Novo et al. 2015).

292 The diffraction pattern of curcumin exhibited peaks at angles $8.59^{\circ}, 11.24^{\circ}, 17.35^{\circ}, 18.19,19.46$, $29321.28^{\circ}, 23.44^{\circ}, 24.58^{\circ}, 25.59^{\circ}, 26.17^{\circ}, 26.79^{\circ}, 27.39^{\circ}, 28.27^{\circ}, 28.97^{\circ}, 31.6^{\circ}$ and $36.23^{\circ}$ which 294 correspond to curcumin polymorph 1, indicating that curcumin sample exists as form 295 1(Poornima et al. 2016; Sanphui et al. 2011). Curcumin exhibited well-defined sharp, narrow 296 diffraction peaks between $10^{\circ}$ and $30^{\circ}$, indicating the high crystalline structure (Cheng et al. 297 2017; Singh et al. 2014). The diffractogram of curcumin incorporated nanocellulose showed 298 peaks which corresponded to both nanocellulose and curcumin. However, the peaks intensity of 299 CNCs decreased after the incorporation of curcumin as shown in Fig. 3 which indicates a low 300 crystallinity of the curcumin incorporated nanocellulose relative to the pure CNCs. From these 301 results, it can be concluded that the interaction of the hydroxyl groups of CNCs with curcumin 302 breaks the intermolecular and intramolecular hydrogen bonds of the CNCs and modifies the 


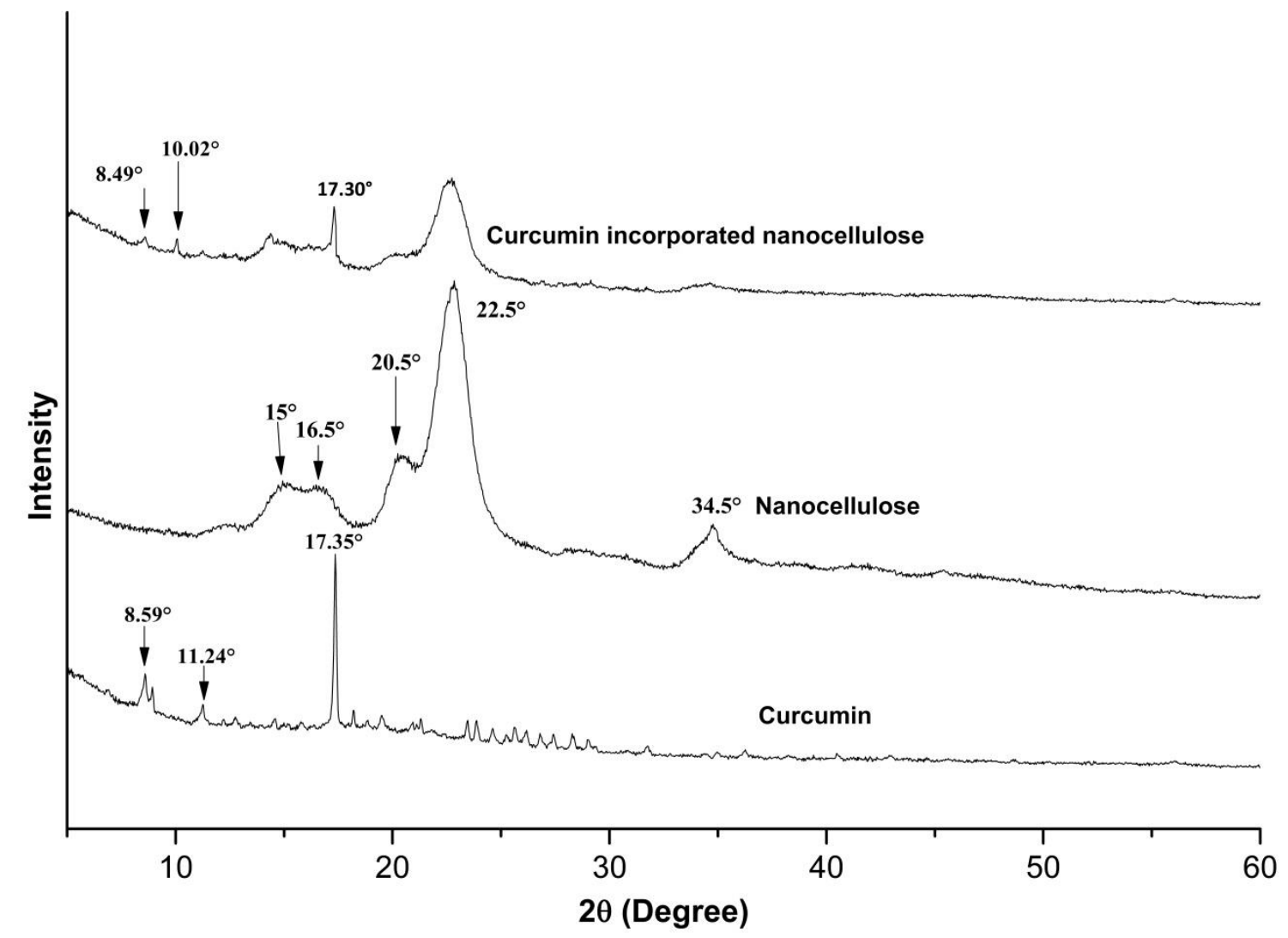

315 Fig. 3 X-ray diffraction (XRD) patterns of curcumin, nanocellulose and curcumin incorporated 316 nanocellulose

\section{Drug loading capacity}

318 Since the solubility of curcumin in water is significantly low, we used nonionic surfactant 319 (Tween 20) to dissolve the curcumin in aqueous medium. After that, the surfactant drug solution 320 was stirred with cellulose nanocrystals to incorporate the drug into nanoparticles. (We used 321 excess amount of curcumin, constant amount of nanocellulose with different concentration of 

nonionic surfactant $(0.8 \%, 1.6 \%, 2.4 \%, 3.2 \%, 4 \%, 4.8 \%, 5.6 \%(\mathrm{w} / \mathrm{v}))$ for the drug loading

323 process. For thecomparison of drug loading capacity, curcumin was incorporated into 324 nanocellulose in methanolic medium. (Here, the same concentration of curcumin and same 325 amount of nanocellulose were used as similar to those used in surfactant solutions). As shown in 326 Fig. 4, the drug loading capacity of nanocellulose increased with increasing the surfactant 327 concentration of the medium.It increased from $0.1 \mathrm{mg} / \mathrm{g}$ to $7.73 \mathrm{mg} / \mathrm{g}$ with increasing the 328 surfactant concentration from $0 \%$ to $4 \%$. The highest drug loading capacity of nanocellulose was 329 given at which the surfactant concentration showed the highest solubility of curcumin. After that, 330 the loading capacity of nanocellulose was not increased with increasing the surfactant 331 concentration. For curcumin dissolved in methanolic medium,the maximum drug loading 332 capacity was $3.35 \mathrm{mg} / \mathrm{g}$. It showed almost two fold increases in the drug loading capacity of 333 nanocellulose in surfactant medium compared to methanolic medium. This may be due to the 334 formation of micelles facilitating the incorporation of drug into nanoparticles.

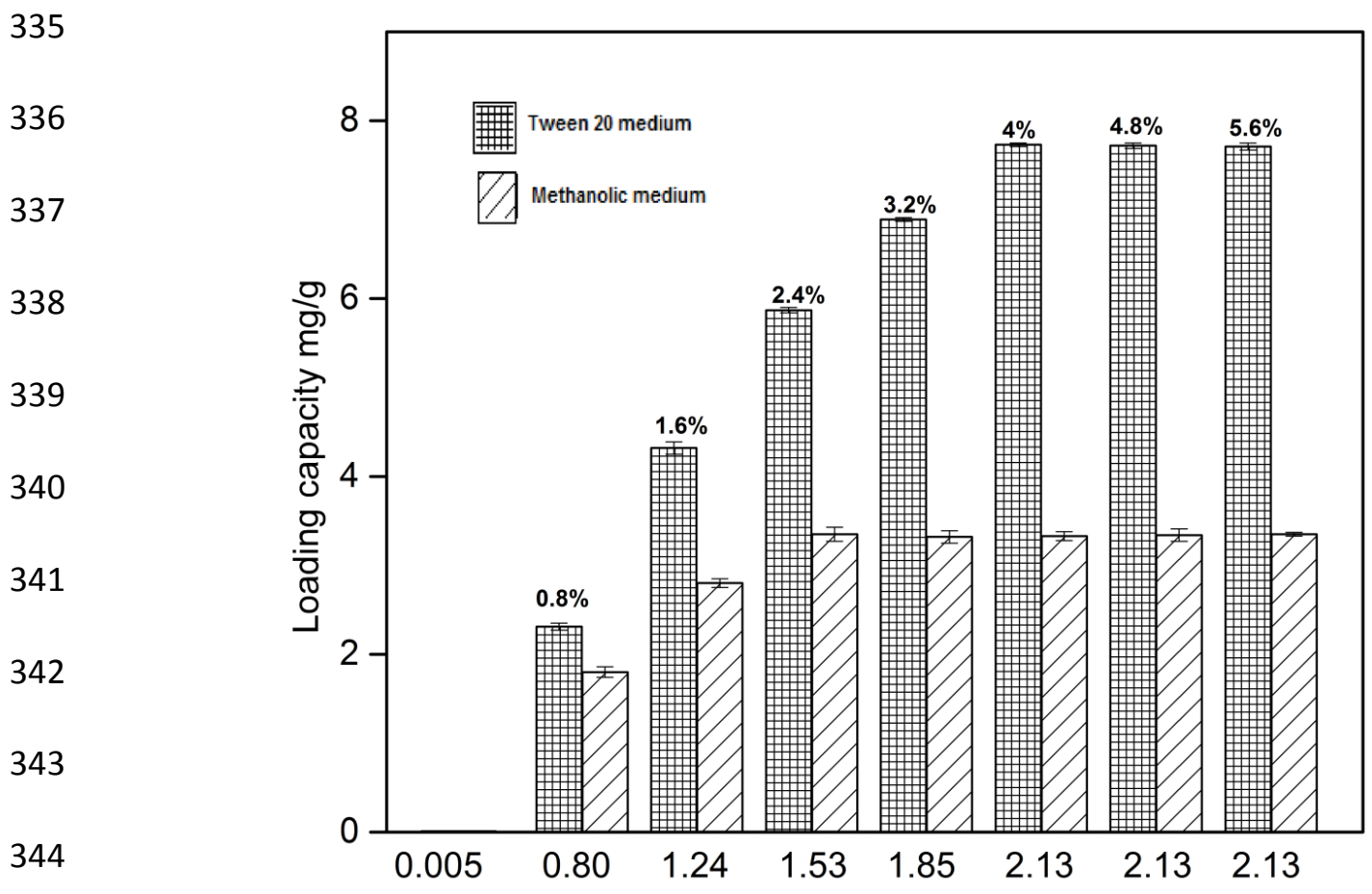

Dissolved curcumin concentration $\mathrm{mg} / \mathrm{mL}$ 
Fig. 4 Drug loading capacity of nanocellulose in surfactant and methanolic medium

347 Surfactant micelles are formed at the critical micelle concentration in aqueous medium due to the 348 attainment of minimum free energy state. The critical micelle concentrations of nonionic 349 surfactants are lower when compared to other ionic surfactants. Most micelles are spherical in 350 shape and contain around 60-100 surfactant molecules. It has the hydrophobic oil-like core 351 formed from the hydrocarbon chains surrounded by hydrophilic head groups of surfactant 352 molecules. Formation of micelle facilitates the incorporation of poorly water- soluble drug in 353 aqueous medium, which result in an increase in the apparent aqueous solubility of the drug.

354 There are number of possible locations of solubilization for a drug in a micelle, depending on 355 their hydrophobicity.

356 As shown in Fig. 5a, hydrophilic drugs can be adsorbed on the surface of hydrophilic head 357 region of the micelle. Drugs with intermediate solubility can be adsorbed between the 358 hydrophilic head groups of surfactant micelle or in the palisade layer which is in between the 359 hydrophilic and the first few carbon atoms of the hydrophobic tail (Fig. 5b,c). Drugs which are 360 highly hydrophobic may be located in the inner core of the micelle. In this case, curcumin is 361 highly hydrophobic and therefore, it may be adsorbed to the inner core of the micelle (Fig. 5d).

362
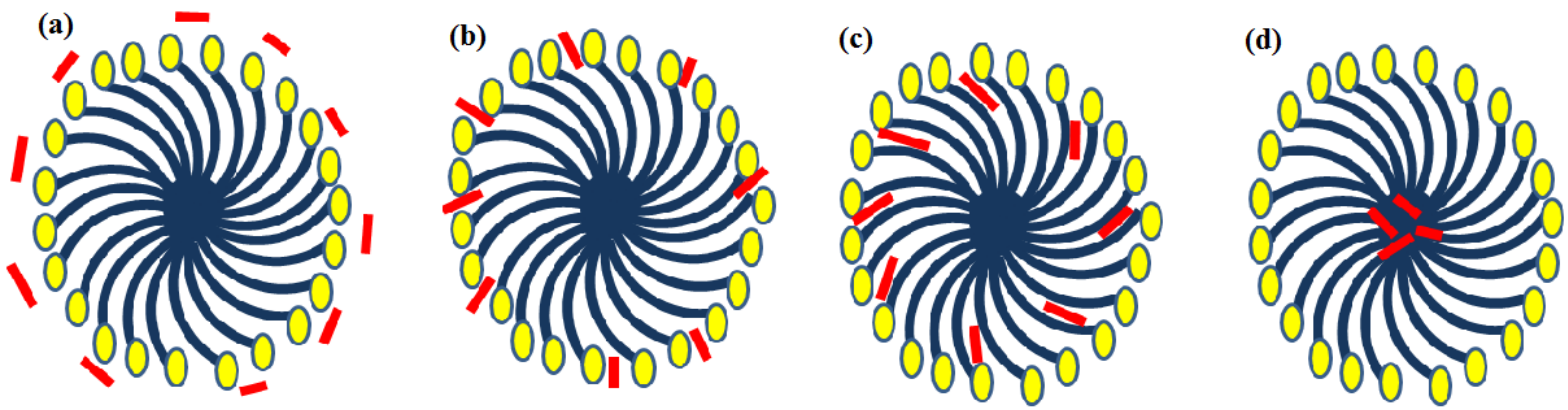
Fig. 5 Possible locations of drug in surfactant micelles, based on the drug hydrophobicity.The red bold lines represent the drug molecules, yellow circles display the surfactant heads and blue curved lines represents the hydrophobic tails of surfactants

Many researches have been discussed chemical strategies for surface modification of nanocelluloses. The main aspect to be considered here is that in contrast to complex chemical

371 modification of cellulose, simple addition of surfactants is an appealing alternative. In

372 suchscenarios, physical adsorption such as charge-charge interactions, association of 373 hydrophobic groups, and hydrogen bonding plays a key role in their association behavior. 374 Adsorbing nonionic surfactantsis a feasible methodto enhance the compatibility of the 375 hydrophilic cellulosic material with the typically hydrophobic materials. The hydrophilic groups 376 of nonionic surfactants may have affinity for adsorption to the cellulose due to the hydroxyl 377 groups of cellulose (as shown in Fig. 6). However, not all the hydroxyl groups present in 378 cellulose nanocrystals are accessible. This is because some of them are oriented towards the 379 inner part of nanoparticle. Previous literature reported that only one half of hydroxyl groups 380 present in cellulose chains of nanoparticle are reactive (Ching et al. 206). It also reported that the 381 primary hydroxyl on C6 is most reactive(Gan et al. 2017).

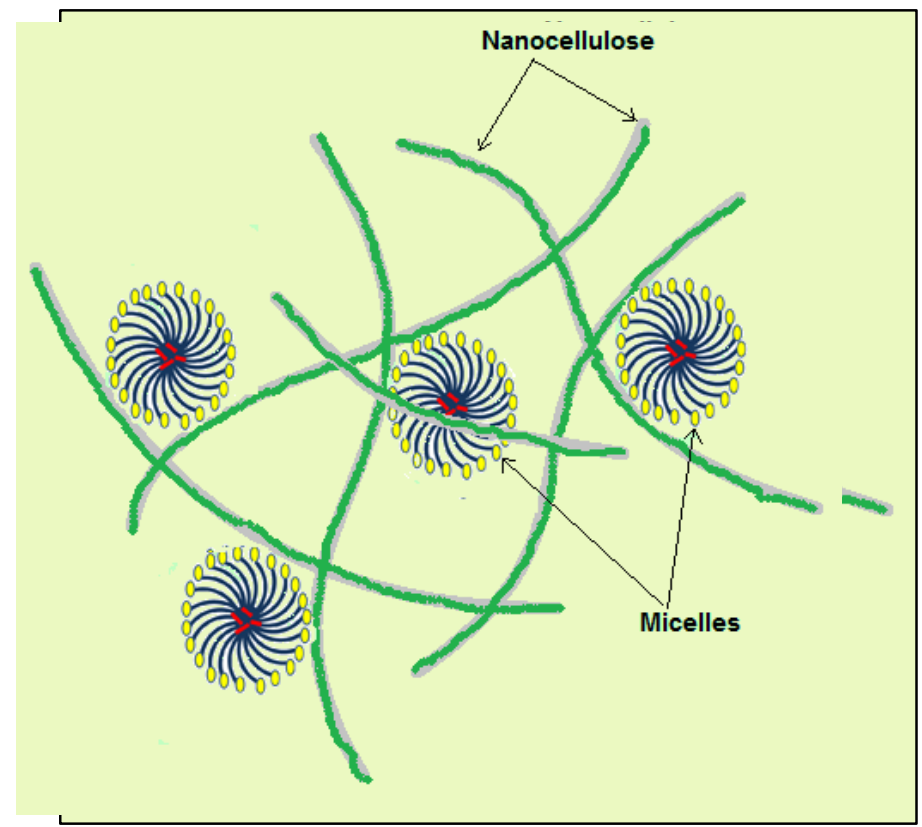


Fig. 6 Possible interactions of surfactant micelles with nanocellulose

389 From previous studies, different types of surfactants have been used to improve the release of 390 drugs in different types of drug delivery systems. Pandav et al. (2013)reported that the 391 encapsulation efficiency of microparticulate drug delivery system of propranolol 392 hydrochloridewas directly proportional to surfactant concentration. Furthermore, Tween80was 393 shownto be themore effective surfactant as comparedto Span 60 for loading of curcumin onto 394 starch nanoparticles(Chin et al. 2014). In our previous study, we observed that the encapsulation 395 efficiency of curcumin in chitosan hydrogel decreased with increasing the surfactant 396 concentration. This was due to the fact that the higher concentration of the emulsifier increases 397 the partition of the drug from internal to external phase due to the increased solubility of the drug 398 in the external phase. But, in this study, the loading capacity of nanocellulose for curcumin 399 increased with increasing the surfactant concentration. This is due to the increase of the number 400 of micelle formation and hence, facilitating the incorporation of drug into nanocellulose 401 particles.

\section{Drug release}

403 Drug release studies were carried out in simulated gastric fluid (SGF) and phosphate buffered 404 saline (PBS) solution. Constant weight of nanoparticles which adsorbed highest amount of 405 curcumin in methanolic medium and Tween 20 medium were selected for drug release studies. 406 All the nanoparticles showed initial burst release during first 30 min due to the fraction of drug 407 which is weekly bound to the large surface area of nanoparticles. As shown in Fig. 7 and Fig.8, 408 among all the nanoparticles, the highest drug release shown by the nanoparticles drug loaded 
insurfactant medium (TW/CNC), compared to the nanoparticles drug loaded in methanolic medium (METH/CNC).The nanoparticles drug loaded in surfactant medium reached to

411 equilibrium drug release stage at around 270 minutes (in SGF medium) and 350 minutes (in PBS

412 medium) while the nanoparticles drug loaded in methanolic medium reached to that stage at

413 around 150 minutes and 270 minutes in SGFand PBS medium respectively. The nanoparticles

414 drug loaded in both surfactant and methanolic medium showed lower drug release in PBS

415 medium. The reason for this may be due to the less stability of curcumin in neutral or pHs above

416 neutral. In addition, previous studies indicated that the stability of curcumin can be strongly

417 improved by lowering the pH of the medium (Khalkhali et al. 2015; Rao and Rao 2011; Wang et

418 al. 1997).
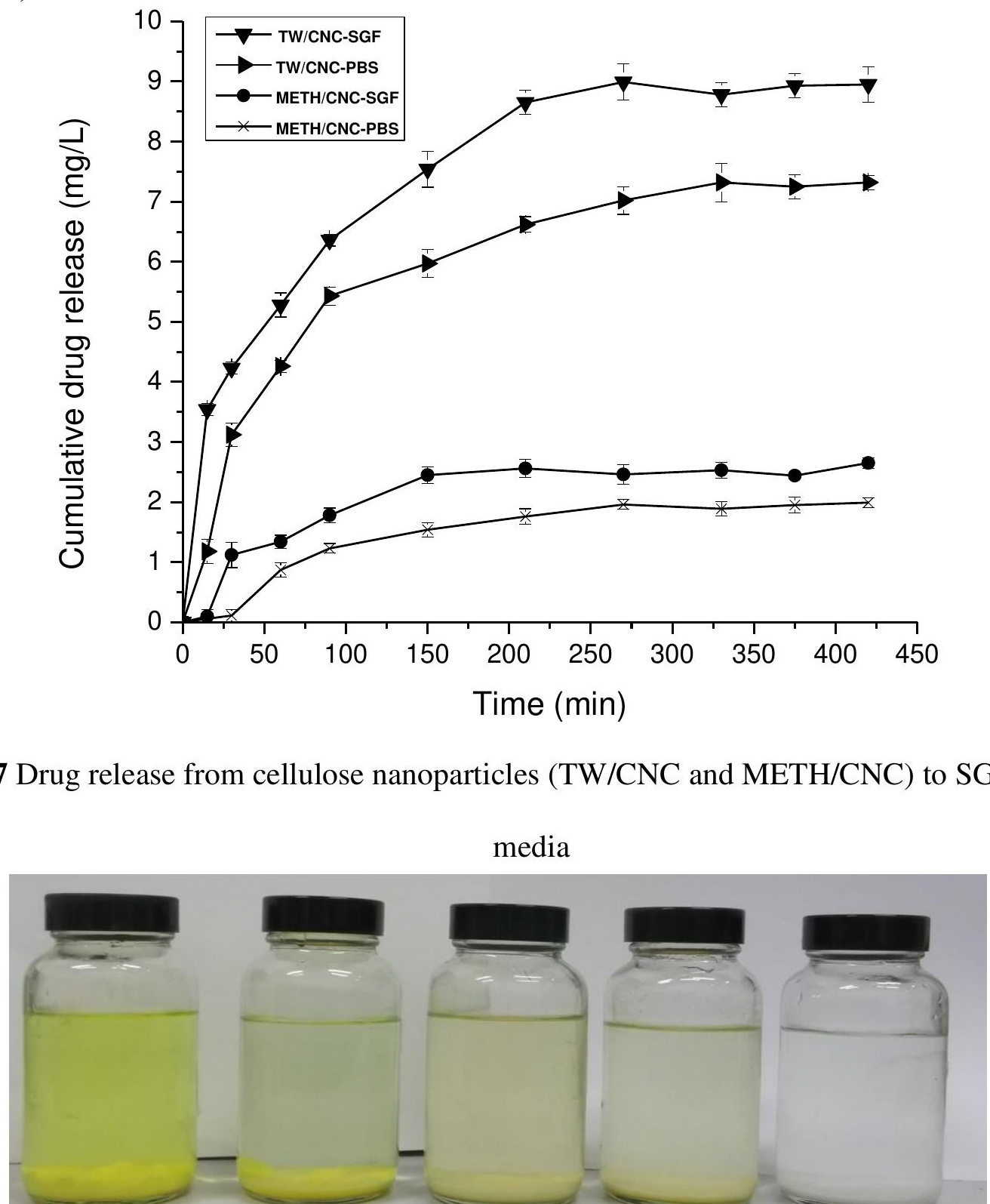
432 Fig. 8 Drug release from: a W/CNC into SGF medium; b METH/CNC into SGF medium; c 433 TW/CNC into PBS medium; d METH/CNC into PBS medium ande control

434 According to our previous study, the nanoparticles prepared by sulphuric acid hydrolysis method 435 were within the range of $200-300 \mathrm{~nm}$ in length and $40-50 \mathrm{~nm}$ in width(Sampath et al. 2017). As 436 the particle size gets smaller, their surface area to volume ratio gets larger. This would imply that 437 more of the drug is closerto the surface of the nanoparticle compared to a larger molecule. Being 438 at or near the surface would lead to faster drug release (Rizvi and Saleh 2017). Average gastric 439 emptying times for healthy individuals at 1, 2, and $4 \mathrm{~h}$ are $>90 \%$, $60 \%$ and $10 \%$, 440 respectively(Jobe et al. 2013). Due to the highest drug release shown in SGF medium, and faster

441 drug release, these drug delivery systems are more suitable for stomach delivery of curcumin.

442 The higher drug release by TW/CNC-SGF and TW/CNC-PBS nanoparticles, which immersed in 443 SGF and PBS media, is due to the presence of adsorbed nonionic surfactants into the 444 nanoparticles. These surfactants facilitate the dispersion of curcumin in aqueous medium. They 445 improve the solubility of poorly water soluble curcumin by formation of micelles and adsorbing 446 the hydrophobic drug into the core of the micelle structure. Hydrophilic head groups show more 447 affinity towards aqueous medium and thereby improve the solubility of the drug in SGF and PBS 448 medium. In contrast, for METH/CNC-SGF and METH/CNC-PBS conditions, the interactions 449 between nanocellulose and curcumin molecules are most probably by hydrogen bonds. Since, 450 there is no micelle formation or facilitation for the dispersion of this poorly water soluble drug, 
451 the release amount of drug to the SGF and PBS medium is very low compared to TW/CNC-SGF 452 and TW/CNC-PBS conditions.

453 Similar drug delivery systems are also reported with enhanced solubility of curcumin using

454 Tween 20. The drug delivery studies on chitin beads incorporated with curcumin, carried out by 455 Ratanajiajaroen and Ohshima (2012)reported that the solubility of curcumin increased up to $4560.767 \mathrm{mg} / \mathrm{mL}$ with the presence of $2 \%(\mathrm{v} / \mathrm{v})$ Tween 20 in acetate buffer medium (pH 5.5). They 457 also found that the drug release rate from chitin beads was proportional to the surfactant 458 concentration. Furthermore, the drug delivery studies on submicrometer spray-dried 459 chitosan/Tween 20 particles byO'Toole et al. (2012) showed that the curcumin can be 460 completely release from the matrix in both phosphate buffered saline solution and $1 \%$ acetic acid 461 over a $2 \mathrm{~h}$ period. In addition, it showed 12.7-fold increase in curcumin solubility with 0.05 $462 \mathrm{w} / \mathrm{v} \%$ of surfactant in $1 \%$ acetic acid solution. From our previous study of curcumin delivery 463 using chitosan/nanocellulose/surfactant hydrogel, we achieved 3.98mg/L of curcumin release in 464 SGF medium after 7.5h. In this study, we achieved $8.99 \mathrm{mg} / \mathrm{L}$ of curcumin release in SGF 465 medium at around 270 minutes. Therefore, these curcumin loaded cellulose nanoparticles 466 provide more effective approach for delivery of curcumin to stomach and upper intestinal tract.

\section{Drug activity}

468 The drugs are often inevitable and therefore, the chemical reactivity related to biological activity 469 of the drug is most important parameter to be concerned when selecting a drug delivery carrier. 470 For some drug delivery systems, drugs deteriorate due to the destructive interactions with the 471 carrier molecules. In order to prevent this, the carrier should be prone to destructive interactions 472 with the drug and able to be delivered into the body without any chemical deterioration. The UV- 
473 Vis spectra of pure drug and released drug can be used to determine if any deterioration reaction

474 happened due to the destructive interactions between drug and carrier molecules (Bashir et al.

475 2016). Curcumin has three reactive functional groups, namely one diketone moiety, and two

476 phenolic groups which associated with its different biological activities. The diketone moiety

477 involves in nucleophilic addition reactions and C-4 participates in hydrogen donation reactions

478 leading to oxidation of curcumin; which are most important chemical reactions associated with

479 its biological activities (Ahmed et al. 2017).

480 As shown in Fig.9a, UV-Vis spectrum of pure curcumin shows an absorption peak around 427

$481 \mathrm{~nm}$, which can be assigned to the low-energy $\pi-\pi^{*}$ excitation of the chromophore, that formed

482 due to the enolization of the diketone group and conjugation between the $\pi$-electron clouds of the

483 two vinylguaiacol (Zsila et al. 2004). In this study, curcumin is in contact with nonionic

484 surfactant, cellulose, simulated gastric fluid and phosphate buffer saline solution. Fig. 9b

485 represents the UV-Vis spectra of curcumin, which is released from nanocellulose (drug loaded in

486 surfactant medium) into simulated gastric medium and phosphate buffered saline solution. It is

487 clear that the absorption maximum of both these spectra is around $427 \mathrm{~nm}$. It remains unchanged

488 without shifting upward or downward regions of the spectrum. Fig. 9c represents the UV-Vis

489 spectra of curcumin, which is released from nanocellulose (drug loaded in methanolic medium)

490 into simulated gastric medium and phosphate buffered saline solution. Since the released amount

491 of drug from these nanoparticles is very low, the absorption peak around $427 \mathrm{~nm}$ is slightly small

492 compared to the absorption maximum of Fig. 9b. However, in this situation the absorption

493 maximum (427 nm) also remain unchanged (without shifting upward or downward direction of

494 the spectrum). Therefore, it revealed that the reactive functional groups, which are associated 
495 with the biological activity of curcumin retained without any deterioration due to any 496 denaturation reaction with drug containing media or with carrier molecules (nanocellulose).

497

498

499

500

501

502

503

504

505

506

507
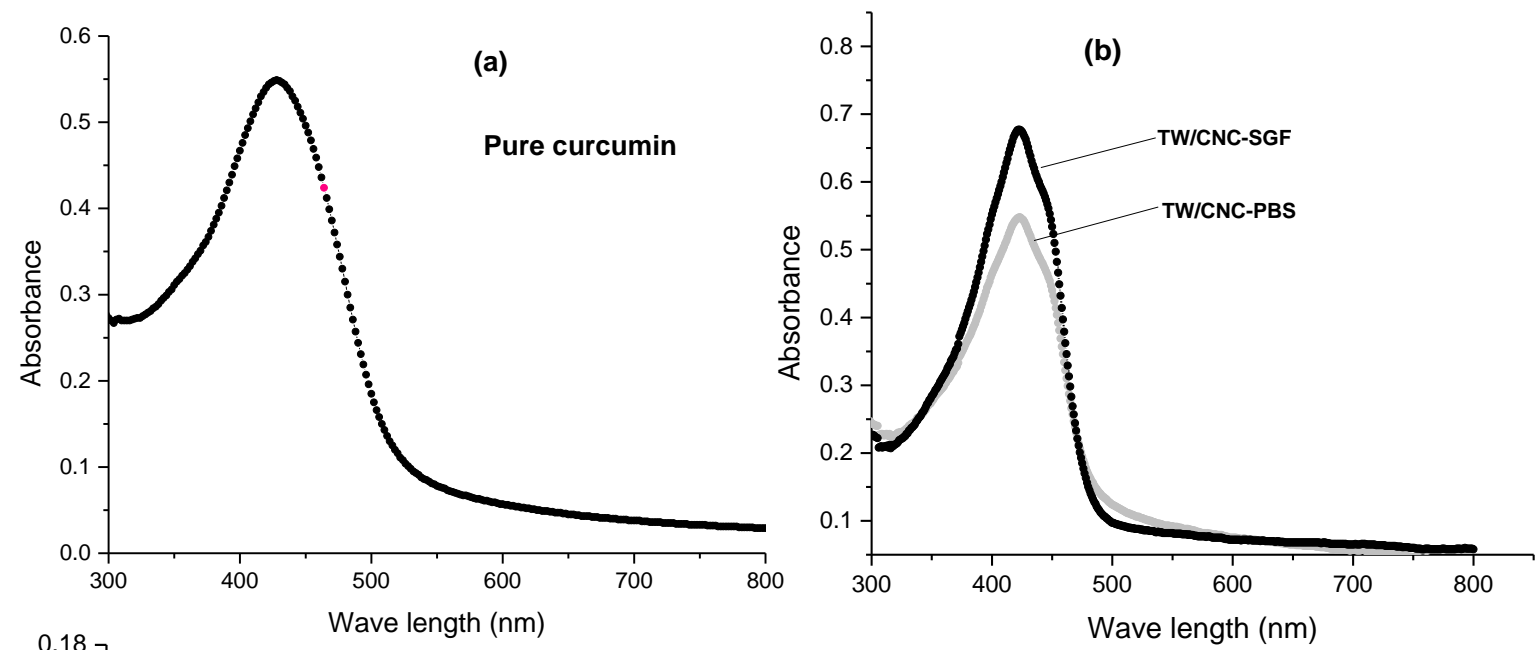

508

509

510

511

512

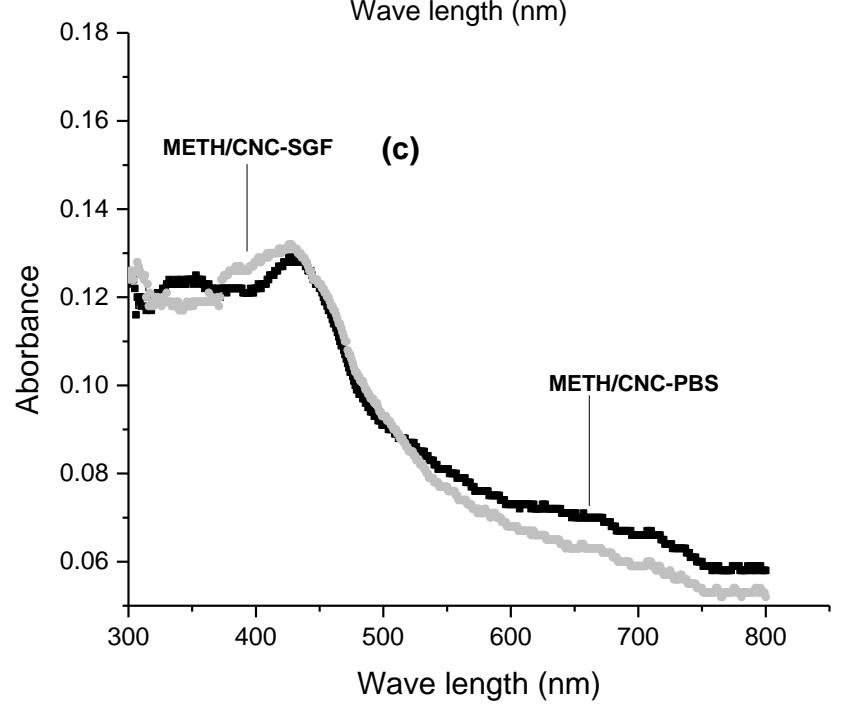

513 Fig. 9 UV-Vis spectra of: a pure curcumin; curcumin release from TW/CNC into PBS and SGF

514 media; c curcumin release from METH/CNC into PBS and SGF media 
516 For the encapsulation of curcumin into nanocellulose, the curcumin was dissolved in surfactant

517 distilled water medium. Therefore, the solubility studies of curcumin were carried out in distilled

518 water with the presence of nonionic surfactantat $37^{\circ} \mathrm{C}$. As shown in Fig. 10 the dissolution rate

519 of curcumin increased with increasing thesurfactant concentration in dissolution medium and the

520 maximum dissolution of curcumin was $2.13 \mathrm{mg} / \mathrm{mL}$ in distilled water containing $4 \% \mathrm{w} / \mathrm{v}$ of

521 surfactant. Addition of surfactant to the distilled water improves the dissolution of pure drug by

522 facilitating the dispersion of drug by micelle solubilization in the bulk medium. The amount of

523 surfactant needed depends on the critical micelle concentration and the solubilization capacity

524 for curcumin in surfactant micelles.It may be the reason for the fact that the amount of dissolved

525 curcumin did not increase above $4 \%$ of surfactant in distilled water. It reached a minimum

526 surface tension at $4 \%$ of surfactantwith no significant change at higher concentrations. Similar

527 results were obtained from the studies on solubility of curcumin in aqueous polysorbate micelle,

528 by Inchai et al. (2015). Their studies showed that the solubility of curcumin increased up to 2.7

$529 \mathrm{mg} / \mathrm{mL}$ in $20 \%$ aqueous solution of Tween 20 . From our previous study, we achieved the

530 solubility of curcumin with an upper limit of $3.014 \pm 0.041 \mathrm{mg} / \mathrm{mL}$ in the presence of $3.2 \%(\mathrm{w} / \mathrm{v})$

531 Tween 20 in simulated gastric medium. This may be due to the higher stability of curcumin in

532 acidic medium compared to neutral or alkaline medium. Previous studies have also confirmed

533 that the aqueous solubility and the stability of curcumin is higher in acidic medium compared to

534 neutral or higher $\mathrm{pH}$ values (Khalkhali et al. 2015; Wang et al. 1997).

535

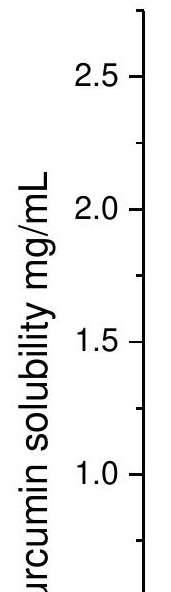


541 Fig. 10Solubility of curcumin in distilled water with different concentrations of nonionic

542 surfactant

\section{Conclusion}

544 Cellulose nanocrystals were synthesized using microcrystalline cellulose via sulphuric acid

545 hydrolysis method. Curcumin was extracted using dried rhizomes of Curcuma longa following 546 the methanolic extraction method. The incorporation of drug and surfactant into the cellulose 547 nanoparticles was verified through the FTIR characterization. The drug loading capacity of 548 nanocellulose increased from $0.1 \mathrm{mg} / \mathrm{g}$ to $7.73 \mathrm{mg} / \mathrm{g}$ with increasing the surfactant concentration 549 from $0 \%$ to $4 \%$. This may be due to the formation of micelles facilitating the incorporation of 550 drug into nanoparticles. The maximum drug loading capacity of nanocellulose in methanolic 551 medium was $3.35 \mathrm{mg} / \mathrm{g}$. Among all the nanoparticles, the highest drug release shown by the 552 nanoparticles drug loaded in surfactant medium (TW/CNC) compared to the nanoparticles drug 553 loaded in methanolic medium (METH/CNC). The nanoparticles drug loaded in both surfactant 554 and methanolic medium showed lower drug release in PBS medium due to the less stability of 555 curcumin in neutral or pHs above neutral. Solubility of curcumin increased with an upper limit of $5562.13 \mathrm{mg} / \mathrm{mL}$ with the presence of $4 \%(\mathrm{w} / \mathrm{v})$ surfactant in distilled water. In addition, curcumin 557 retained its structural integrity after release to the SGF and PBS media, which is a critical 
requirement for preserving drug activity. In conclusion, the enhancement of bioavailability of curcumin using curcumin/nonionic surfactant-incorporated cellulose nanoparticles would represent an important step forward in nanopharmaceutical field.

\section{Acknowledgments}

The authors would like to acknowledge the financial support from the Ministry of Education of Malaysia FRGS-FP053-2015A and PRGS-PR005-2017A and University of Malaya PG1602016A, ST017-2018, GPF 033A-2018, RU018I-2016 and International Funding AUA Scholars IF025-2018 for the success of this project.

\section{References}

Ahmed M, Qadir MA, Shafiq MI, Muddassar M, Hameed A, Arshad MN, Asiri AM (2017) Curcumin: Synthesis optimization and in silico interaction with cyclin dependent kinase. Acta Pharmaceut 67:385-395

Bashir S, Teo YY, Ramesh S, Ramesh K (2016) Synthesis, characterization, properties of Nsuccinyl chitosan-g-poly (methacrylic acid) hydrogels and in vitro release of theophylline. Polymer 92:36-49

Bich VT, Thuy NT, Binh NT, Huong NTM, Yen PND, Luong TT (2009) Structural and spectral properties of curcumin and metal-curcumin complex derived from turmeric (Curcuma longa). In: Cat DT, Pucci A, Wandelt K (eds) Physics and engineering of new materials. Springer proceedings in physics. Springer, Berlin, pp 271-278

Chaudhari SP, Dugar RP (2017) Application of surfactants in solid dispersion technology for improving solubility of poorly water soluble drugs. J Drug Deliv Sci Tec 41:68-77

Cheng C, Peng S, Li Z, Zou L, Liu W, Liu C (2017) Improved bioavailability of curcumin in liposomes prepared using a $\mathrm{pH}$-driven, organic solvent-free, easily scalable process. Rsc Adv 7:25978-25986

Chin SF, Yazid M, Akmar SN, Pang SC (2014) Preparation and characterization of starch nanoparticles for controlled release of curcumin. Int J Polym Sci 2014:340121

Ching YC, Md. Ershad MA, Luqman CA, Choo KW, Yong C K, Sabariah JJ, Chuah CH, Liou NS (2016) Rheological properties of cellulose nanocrystal-embedded polymer composites: a review. Cellulose 23:1011-1030.

Ching YC and Ng TS (2014). Effect of preparation conditions on cellulose from oil palm empty fruit bunch fiber. Bioresource 9(4): 6373- 6385

de Castro DO, Tabary N, Martel B, Gandini A, Belgacem N, Bras J (2018) Controlled release of carvacrol and curcumin: bio-based food packaging by synergism action of TEMPOoxidized cellulose nanocrystals and cyclodextrin. Cellulose 25:1249-1263 
De R, Kundu P, Swarnakar S, Ramamurthy T, Chowdhury A, Nair GB, Mukhopadhyay AK (2009) Antimicrobial activity of curcumin against Helicobacter pylori isolates from India and during infections in mice. Antimicrob Agents Ch 53:1592-1597

Fugita RA, Gálico DA, Guerra RB, Perpétuo GL, Treu-Filho O, Galhiane MS, Mendes RA, Bannach G (2012) Thermal behaviour of curcumin. Braz J Therm Anal 1:19-23

Gan S, Zakaria S, Chia CH, Chen RS, Ellis AV, Kaco H (2017) Highly porous regenerated cellulose hydrogel and aerogel prepared from hydrothermal synthesized cellulose carbamate. PLoS One 12:e0173743

Gunathilake TMSU, Ching YC, Chuah CH (2017) Enhancement of curcumin bioavailability using nanocellulose reinforced chitosan hydrogel. Polymers 9:64

Gunathilake TMSU, Ching YC, Chuah CH, Illias HA, Ching KY, Singh R, Nai-Shang L (2018) Influence of a nonionic surfactant on curcumin delivery of nanocellulose reinforced chitosan hydrogel. Int J Biol Macromol 118:1055-1064

Gunathilake T M SU, Ching YC, Kuan YC, Chuah CH and Luqman CH (2017) Biomedical and microbiological applications of bio-based porous materials: a review. Polymer, 9: 160. doi:10.3390/polym9050160

Gustafson HH, Holt-Casper D, Grainger DW, Ghandehari H (2015) Nanoparticle uptake: the phagocyte problem. Nano today 10:487-510

Ibrahim S, Tagami T, Kishi T, Ozeki T (2018) Curcumin marinosomes as promising nano-drug delivery system for lung cancer. Int J Pharmaceut 540:40-49

Inchai N, Ezure Y, Hongwiset D, Yotsawimonwat S (2015) Investigation on solubility and stability of curcumin in aqueous polysorbate micelle. International Journal of Management and Applied Science 3:157-161

Jankun J, Wyganowska-Świątkowska M, Dettlaff K, Jelińska A, Surdacka A, WątróbskaŚwietlikowska D, Skrzypczak-Jankun E (2016) Determining whether curcumin degradation/condensation is actually bioactivation. Int J Mol Med 37:1151-1158

Jobe BA, Richter JE, Hoppo T, Peters JH, Bell R, Dengler WC, DeVault K, Fass R, Gyawali CP, Kahrilas PJ, Lacy BE, Pandolfino JE, Patti MG, Swanstrom LL, Kurian AA, Vela MF, Vaezi M, DeMeester TR (2013) Preoperative diagnostic workup before antireflux surgery: An evidence and experience-based consensus of the esophageal diagnostic advisory panel. J Am Coll Surgeons 217:586-597

Kamaraj S, Palanisamy UM, Mohamed MSBK, Gangasalam A, Maria GA, Kandasamy R (2018) Curcumin drug delivery by vanillin-chitosan coated with calcium ferrite hybrid nanoparticles as carrier. Eur J Pharm Sci 116:48-60

Khalkhali M, Sadighian S, Rostamizadeh K, Khoeini F, Naghibi M, Bayat N, Habibizadeh M, Hamidi M (2015) Synthesis and characterization of dextran coated magnetite nanoparticles for diagnostics and therapy. Bioimpacts 5:141

Kolev TM, Velcheva EA, Stamboliyska BA, Spiteller M (2005) DFT and experimental studies of the structure and vibrational spectra of curcumin. Int J Quantum Chem 102:1069-1079

Löbmann K, Svagan AJ (2017) Cellulose nanofibers as excipient for the delivery of poorly soluble drugs. Int J Pharmaceut 533:285-297

Mohan PK, Sreelakshmi G, Muraleedharan C, Joseph R (2012) Water soluble complexes of curcumin with cyclodextrins: Characterization by FT-Raman spectroscopy. Vib Spectrosc 62:77-84 
Yallapu MM, Dobberpuhl MR, Maher DM, Jaggi M, Chauhan SC (2012) Design of curcumin loaded cellulose nanoparticles for prostate cancer. Curr Drug Metab 13:120-128

Novo LP, Bras J, García A, Belgacem N, Curvelo AA (2015) Subcritical water: a method for green production of cellulose nanocrystals. ACS Sustain Chem Eng 3:2839-2846

Ntoutoume GMAN, Granet R, Mbakidi JP, Brégier F, Léger DY, Fidanzi-Dugas C, Lequart V, Joly N, Liagre B, Chaleix V, Sol V (2016) Development of curcumincyclodextrin/cellulose nanocrystals complexes: new anticancer drug delivery systems. Bioorg Med Chem Lett 26:941-945

O’Toole MG, Henderson RM, Soucy PA, Fasciotto BH, Hoblitzell PJ, Keynton RS, Ehringer WD, Gobin AS (2012) Curcumin encapsulation in submicrometer spray-dried chitosan/Tween 20 particles. Biomacromolecules 13:2309-2314

Ortiz-Tafoya M, Tecante A (2018) Physicochemical characterization of sodium stearoyl lactylate (SSL), polyoxyethylene sorbitan monolaurate (Tween 20) and $\kappa$-carrageenan. Data Brief 19:642-650

Pandav S, Lokhande A, Naik J (2013) Assessment of microparticulate drug delivery system of propranolol hydrochloride prepared by multiple solvent emulsion technique. Int J Pharm Pharm Sci 5:831-835

Phanthong P, Ma Y, Guan G, Abudula A (2015) Extraction of nanocellulose from raw apple stem. Journal of the Japan Institute of Energy 94:787-793

Poornima B, Prasad K, Bharathi K (2016) Evaluation of solid-state forms of curcuminoids. Int J Pharm Sci Res 7:4035

Rangel-Yagui CO, Pessoa Jr A, Tavares LC (2005) Micellar solubilization of drugs. J Pharm Pharm Sci 8:147-163

Rao JV, Rao M (2011) Increased solubility and stability of curcumin in lactic acid. Int J Pharm Bio Sci 1:50-53

Ratanajiajaroen P, Ohshima M (2012) Synthesis, release ability and bioactivity evaluation of chitin beads incorporated with curcumin for drug delivery applications. J Microencapsul 29:549-558

Rizvi SA, Saleh AM (2017) Applications of nanoparticle systems in drug delivery technology. Saudi Pharm J 26(1): 64-70

Sadeghifar H, Filpponen I, Clarke SP, Brougham DF, Argyropoulos DS (2011) Production of cellulose nanocrystals using hydrobromic acid and click reactions on their surface. $\mathrm{J}$ Mater Sci 46:7344-7355

Sahlin K, Forsgren L, Moberg T, Bernin D, Rigdahl M, Westman G (2018) Surface treatment of cellulose nanocrystals (CNC): effects on dispersion rheology. Cellulose 25:331-345

Sampath UTM, Ching YC, Chuah CH, Singh R, Lin PC (2017) Preparation and characterization of nanocellulose reinforced semi-interpenetrating polymer network of chitosan hydrogel. Cellulose 24:2215-2228

Sanphui P, Goud NR, Khandavilli UR, Bhanoth S, Nangia A (2011) New polymorphs of curcumin. Chem Commun 47:5013-5015

Santos AM, Lopes T, Oleastro M, Pereira T, Alves CC, Seixas E, Chaves P, Machado J, Guerreiro AS (2018) Cyclooxygenase inhibition with curcumin in Helicobacter pylori infection. Nutrire 43:7

Singh PK, Wani K, Kaul-Ghanekar R, Prabhune A, Ogale S (2014) From micron to nanocurcumin by sophorolipid co-processing: highly enhanced bioavailability, fluorescence, and anti-cancer efficacy. Rsc Adv 4:60334-60341 
Wang YJ, Pan MH, Cheng AL, Lin LI, Ho YS, Hsieh CY, Lin JK (1997) Stability of curcumin in buffer solutions and characterization of its degradation products. J Pharmaceut Biomed 15:1867-1876

Zsila F, Bikádi Z, Simonyi M (2004) Circular dichroism spectroscopic studies reveal pH dependent binding of curcumin in the minor groove of natural and synthetic nucleic acids. Org Biomol Chem 2:2902-2910

\section{List of figures}

Fig. 1 FTIR spectra of curcumin, nonionic surfactant and nanocellulose (CNC)

Fig. 2 FTIR spectra of cellulose nanoparticles, curcumin loaded cellulose nanoparticles in methanolic medium and curcumin loaded cellulose nanoparticles in surfactant medium

Fig. 3 X-ray diffraction (XRD) patterns of curcumin, nanocellulose and curcumin incorporated nanocellulose

Fig. 4Drug loading capacity of nanocellulose in surfactant and methanolic medium

Fig. 5 Possible locations of drug in surfactant micelles based on the drug hydrophobicity. The red bold lines represent the drug molecules, yellow circles display the surfactant heads and blue curved lines represents the hydrophobic tails of surfactants

Fig. 6 Possible interactions of surfactant micelles with nanocellulose

Fig. 7 Drug release from cellulose nanoparticles (TW/CNC and METH/CNC) to SGF and PBS media

Fig. 8Drug release from: a TW/CNC into SGF medium; b METH/CNC into SGF medium; c TW/CNC into PBS medium; $\mathbf{d}$ METH/CNC into PBS medium and e control

Fig. 9 UV-Vis spectra of: a pure curcumin; b curcumin release from TW/CNC into PBS and SGF media; c curcumin release from METH/CNC into PBS and SGF media 
709 Fig. 10 Solubility of curcumin in distilled water with different concentrations of nonionic

710 surfactant

\section{$711 \quad$ List of Tables}

712 Table 1 Types of nanocellulose used for the drug release studies (based on the drug loading and 713 releasing medium)

714

715

716

717

718 


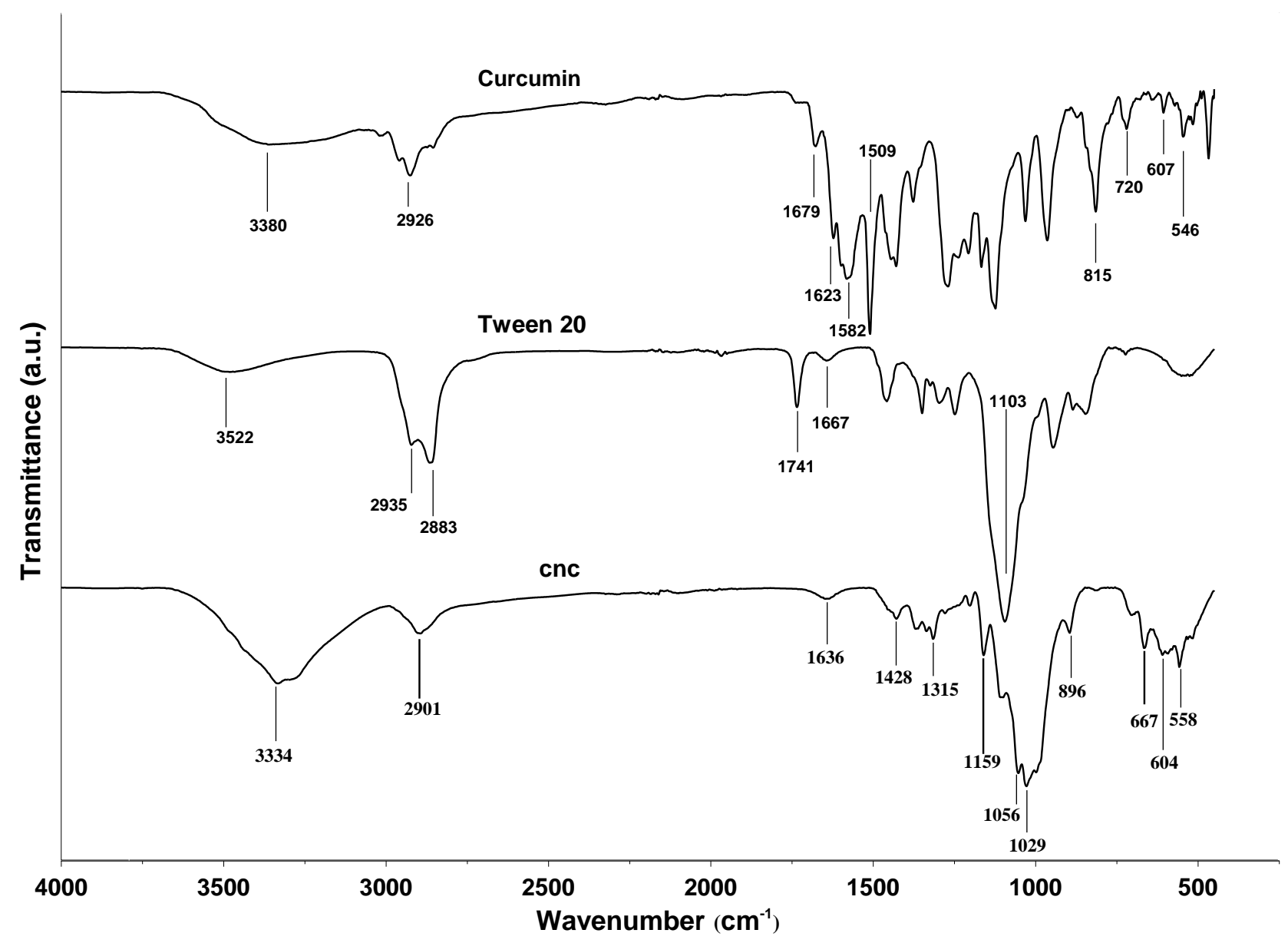

Fig. 1 FTIR spectra of curcumin, nonionic surfactant and nanocellulose (CNC) 


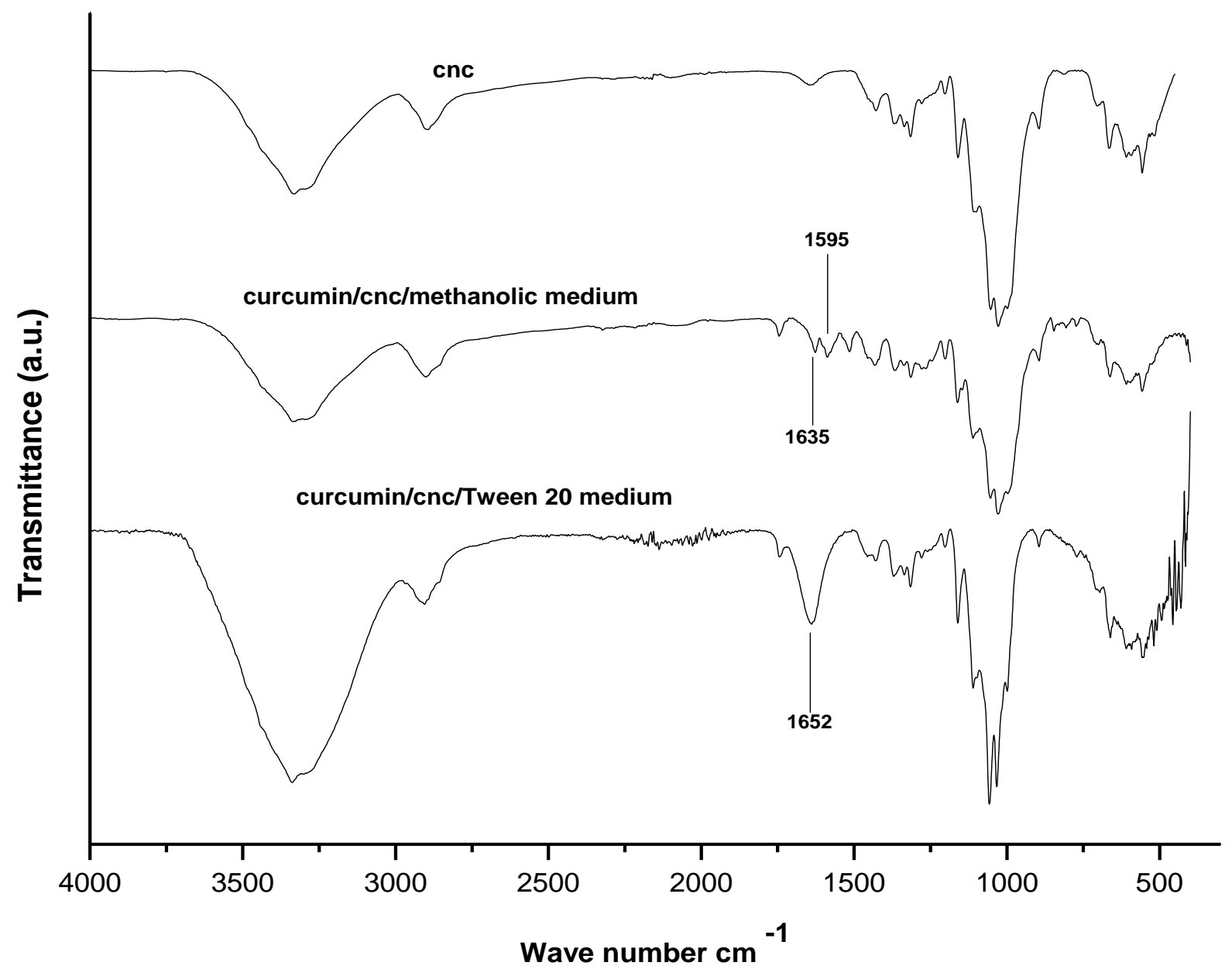

Fig. 2 FTIR spectra of cellulose nanoparticles, curcumin loaded cellulose nanoparticles in methanolic medium and curcumin loaded cellulose nanoparticles in surfactant medium 


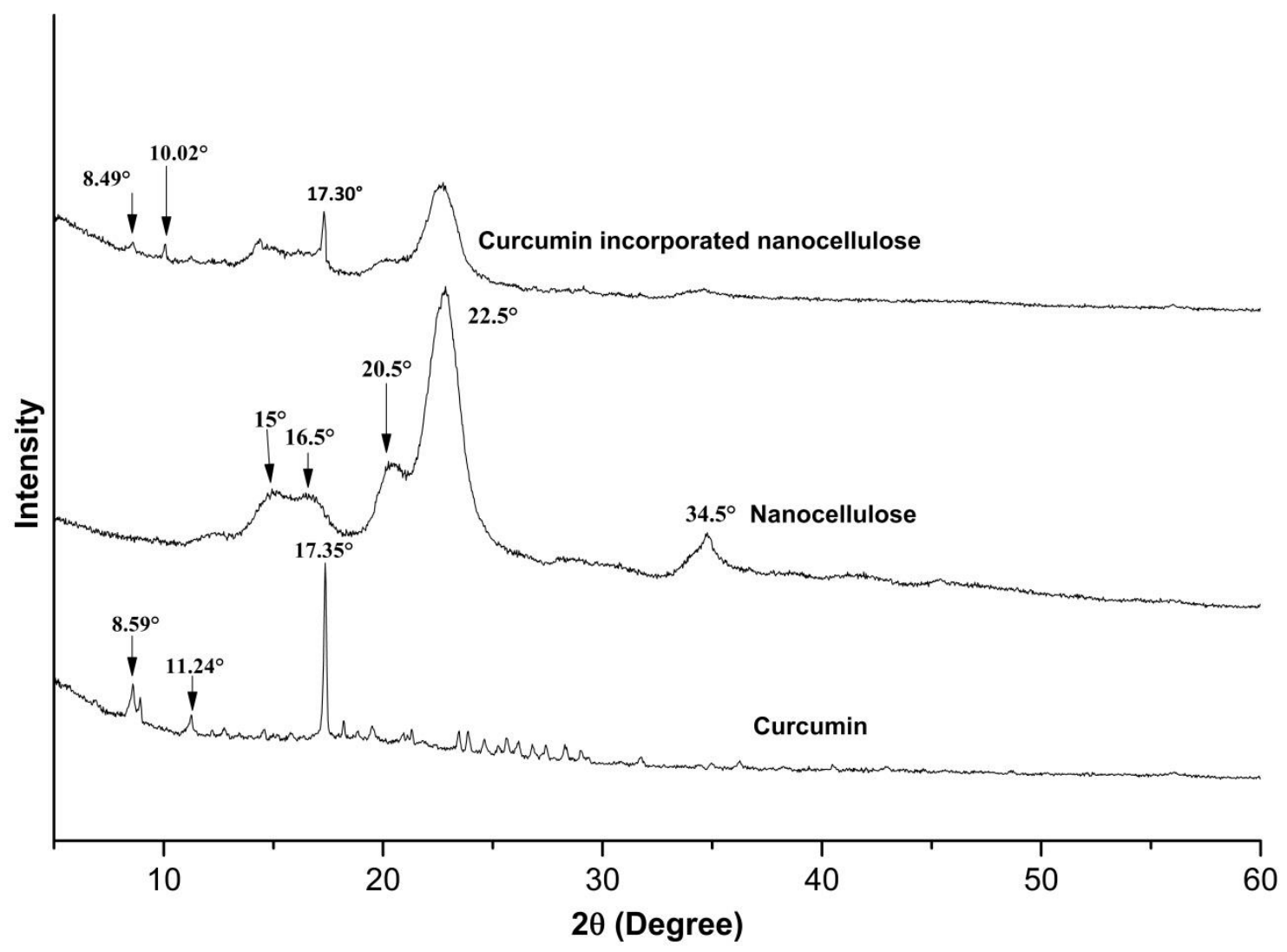

Fig. 3 X-ray diffraction (XRD) patterns of curcumin, nanocellulose and curcumin incorporated nanocelulose 


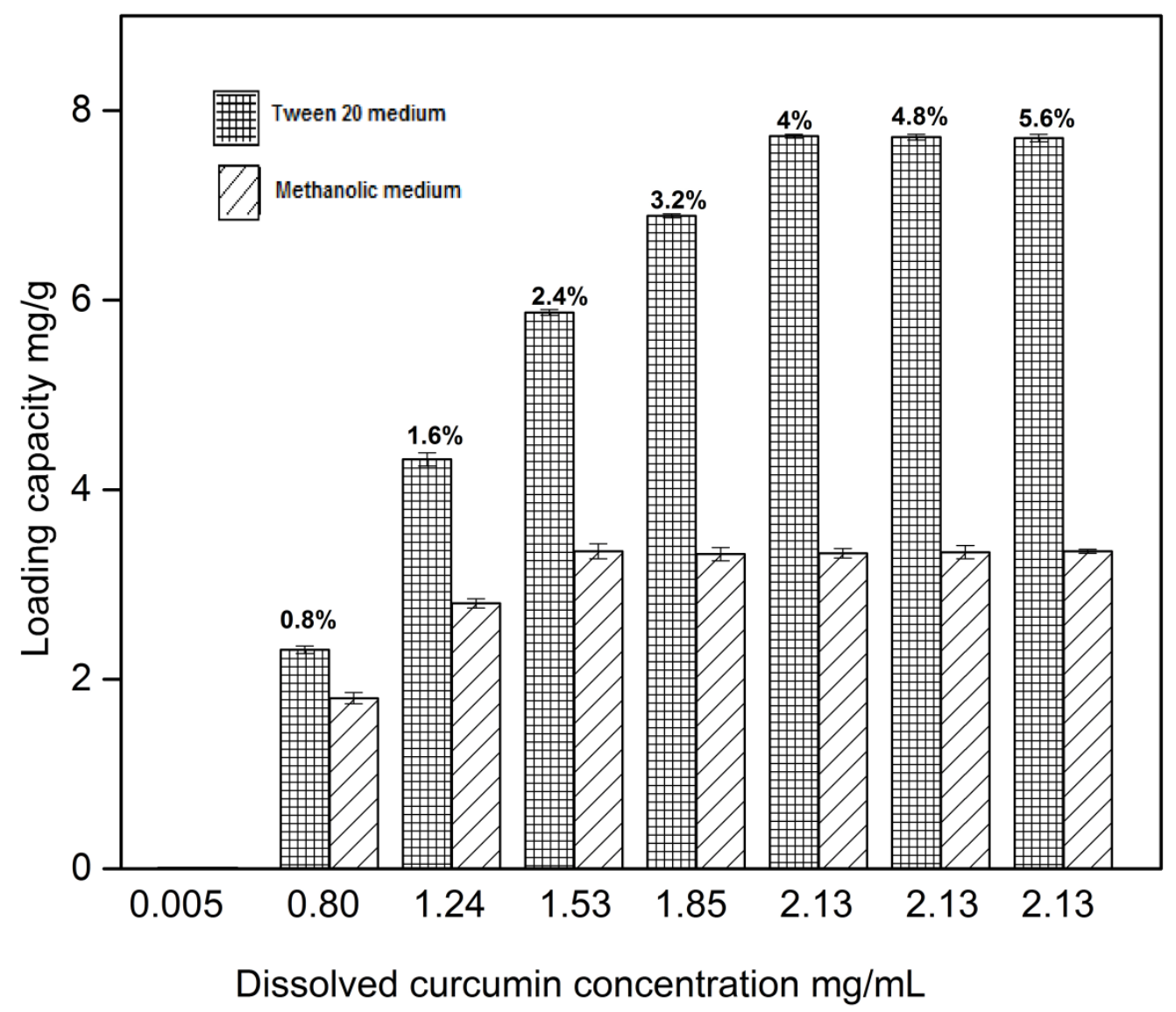

Fig. 4 Drug loading capacity of nanocellulose in surfactant and methanolic medium 

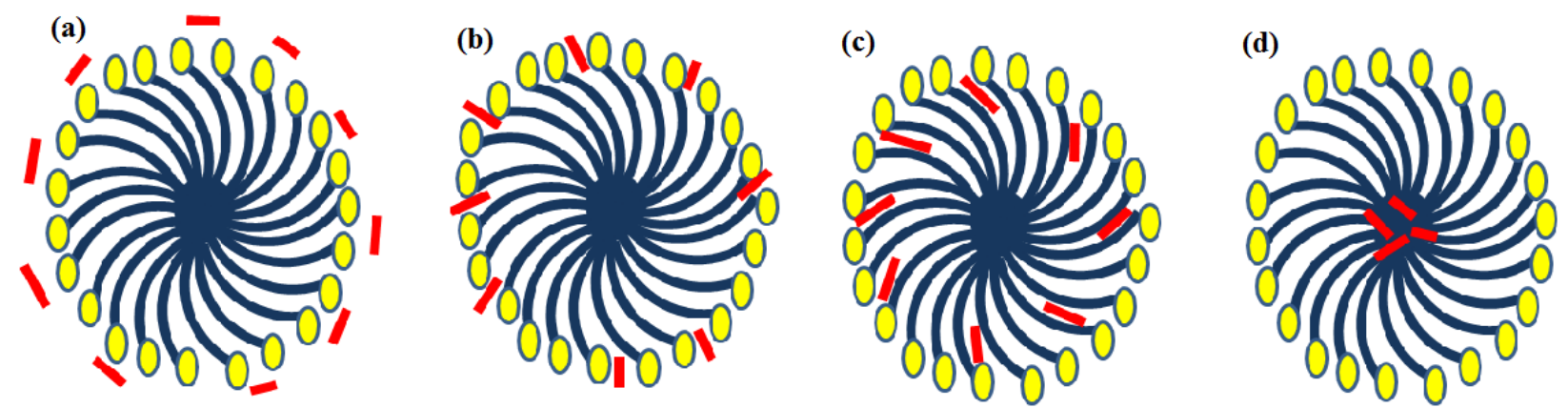

Fig. 5 Possible locations of drug in surfactant micelles, based on the drug hydrophobicity. The red bold lines represent the drug molecules, yellow circles display the surfactant heads and blue curved lines represents the hydrophobic tails of surfactants 


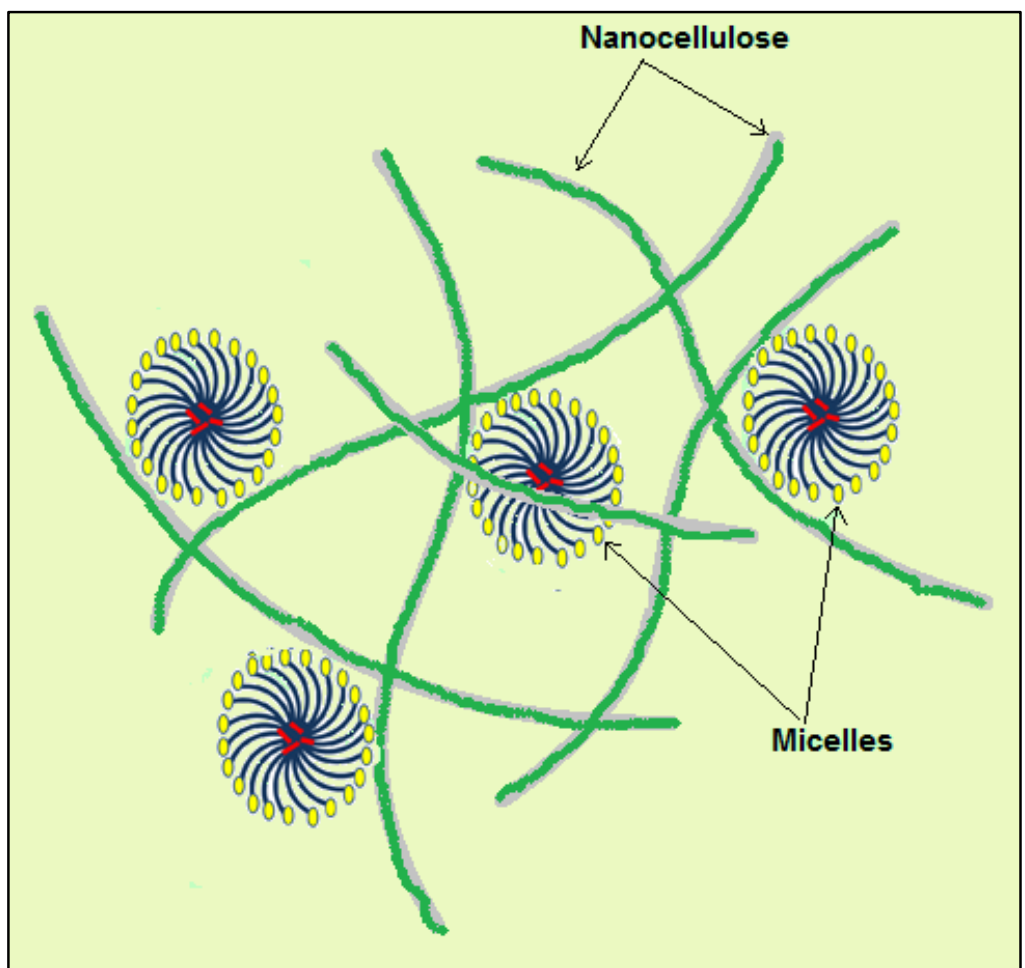

Fig. 6 Possible interactions of surfactant micelles with nanocellulose 


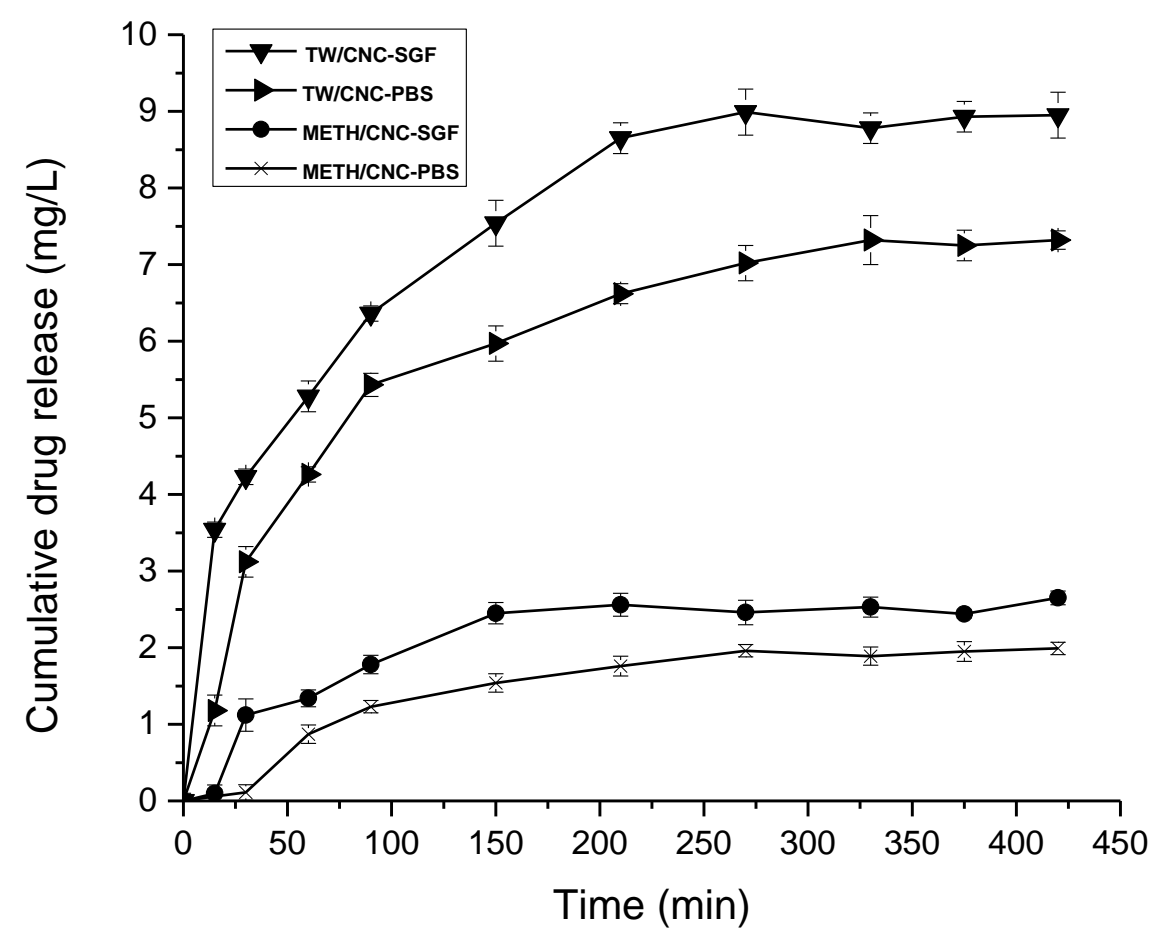

Fig. 7 Drug release from cellulose nanoparticles (TW/CNC and METH/CNC) to SGF and PBS media 


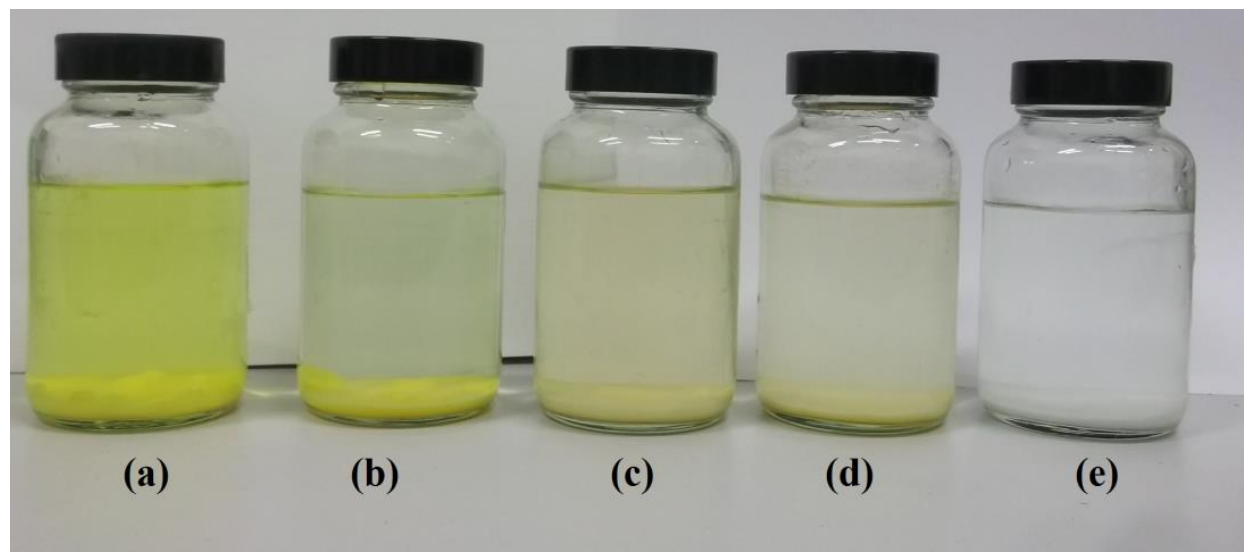

Fig. 8 Drug release from: a TW/CNC into SGF medium; b METH/CNC into SGF medium; c TW/CNC into PBS medium; d METH/CNC into PBS medium and e control 

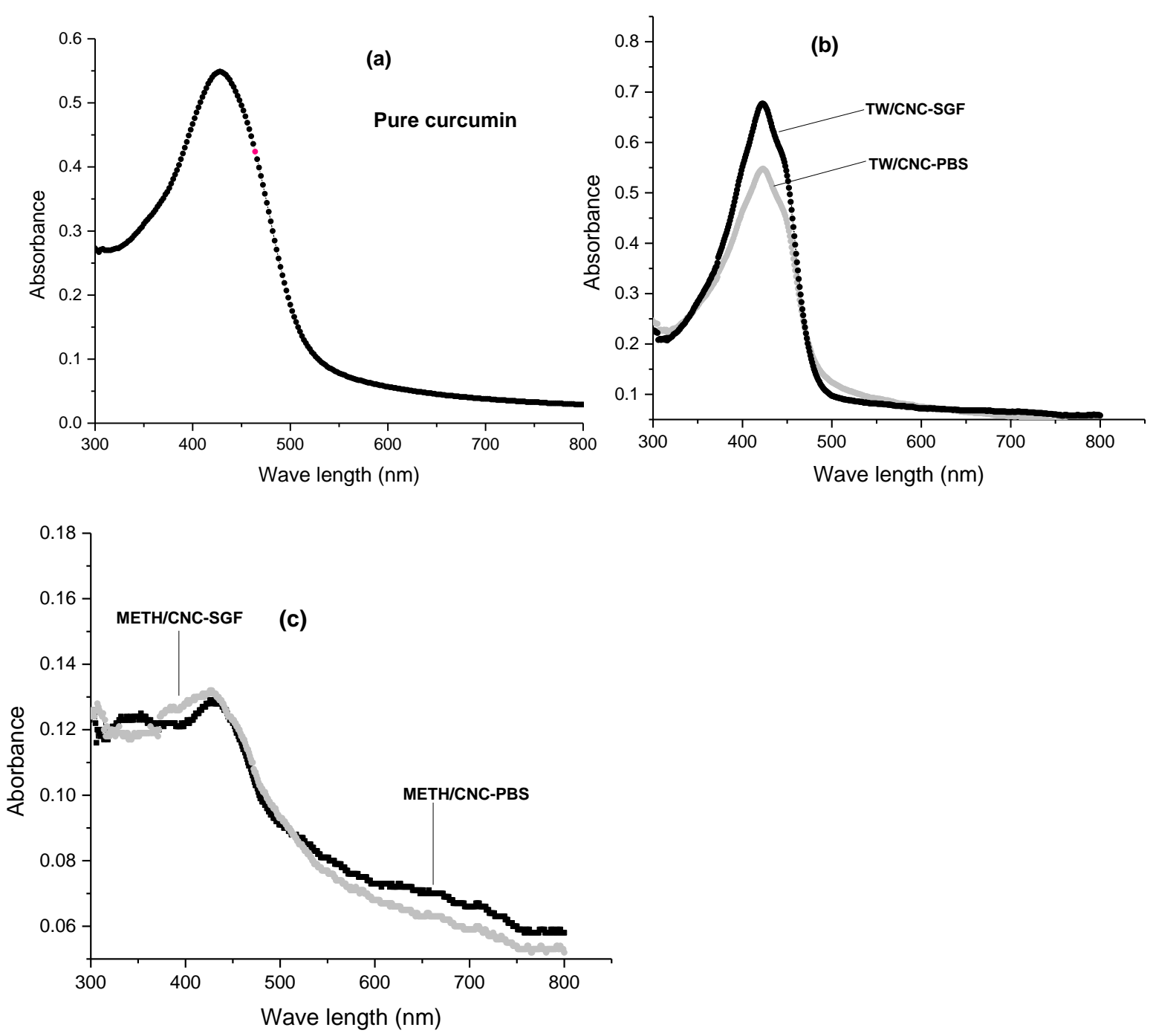

Fig. 9 UV-Vis spectra of: a pure curcumin; b curcumin release from TW/CNC into PBS and SGF media; c curcumin release from METH/CNC into PBS and SGF media 


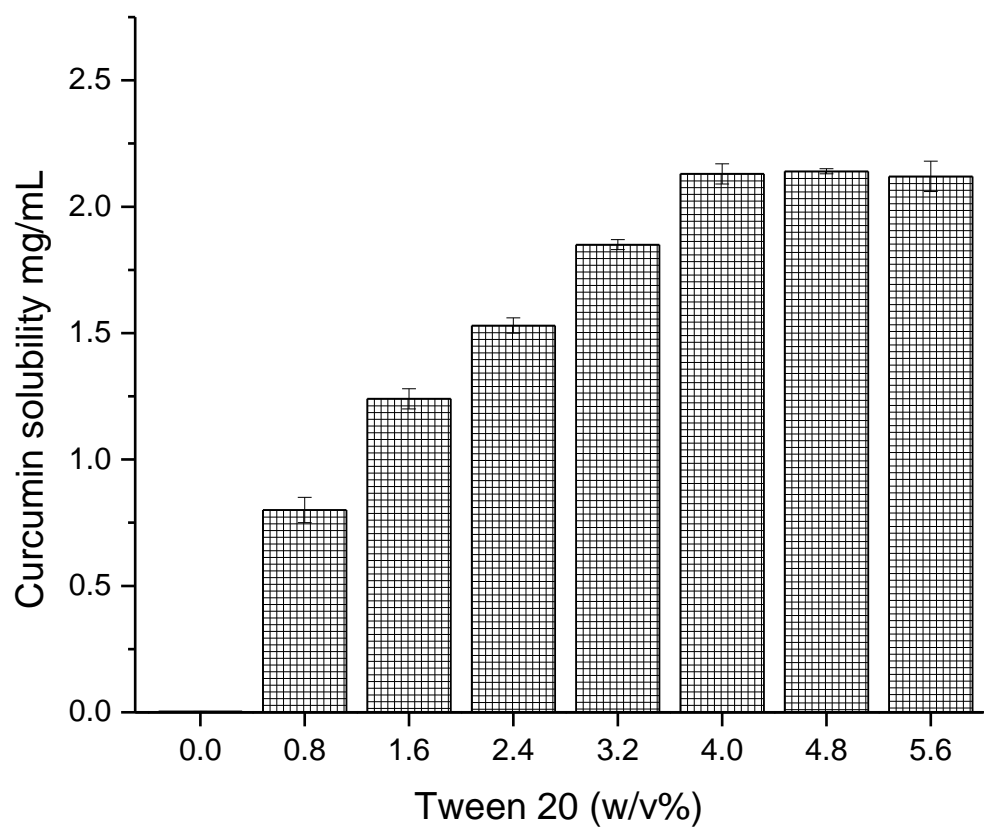

Fig. 10 Solubility of curcumin in distilled water with different concentrations of nonionic surfactant 
Table 1 Types of nanocellulose used for the drug release studies (based on the drug loading and releasing medium)

\begin{tabular}{|l|c|l|l|l|}
\hline $\begin{array}{l}\text { Types of nanocellulose } \\
\text { (based on the drug } \\
\text { loading and releasing } \\
\text { medium) }\end{array}$ & $\begin{array}{l}\text { Weight of } \\
\text { nanocellulose }(\mathrm{g})\end{array}$ & $\begin{array}{l}\text { Amount of drug } \\
\text { (curcumin) } \\
\text { loaded per 1 g } \\
\text { of nanocellulose } \\
\text { (mg) }\end{array}$ & $\begin{array}{l}\text { Drug loading } \\
\text { medium }\end{array}$ & $\begin{array}{l}\text { Drug releasing } \\
\text { medium }\end{array}$ \\
\hline TW/CNC-SGF & 1 & 7.73 & $\begin{array}{l}\text { Aqueous } \\
\text { solution of } \\
\text { Tween 20 }\end{array}$ & $\begin{array}{l}\text { Simulated } \\
\text { gastric fluid }\end{array}$ \\
\hline TW/CNC-PBS & 1 & 7.73 & $\begin{array}{l}\text { Aqueous } \\
\text { solution of } \\
\text { Tween 20 }\end{array}$ & $\begin{array}{l}\text { Phosphate } \\
\text { buffered saline } \\
\text { solution }\end{array}$ \\
\hline METH/CNC-SGF & 1 & 3.35 & $\begin{array}{l}\text { Methanolic } \\
\text { medium }\end{array}$ & $\begin{array}{l}\text { Simulated } \\
\text { gastric fluid }\end{array}$ \\
\hline METH/CNC-PBS & 1 & 3.35 & $\begin{array}{l}\text { Methanolic } \\
\text { medium }\end{array}$ & $\begin{array}{l}\text { Phosphate } \\
\text { buffered saline } \\
\text { solution }\end{array}$ \\
\hline
\end{tabular}

